\title{
\begin{tabular}{l|l} 
Mibraries & DSpace@MIT
\end{tabular}
}

\author{
MIT Open Access Articles
}

\section{Caged Mono- and Divalent Ligands for Light-Assisted Disruption of PDZ Domain-Mediated Interactions}

The MIT Faculty has made this article openly available. Please share how this access benefits you. Your story matters.

Citation: Sainlos, Mathieu, Wendy S. Iskenderian-Epps, Nelson B. Olivier, Daniel Choquet, and Barbara Imperiali. "Caged Mono- and Divalent Ligands for Light-Assisted Disruption of PDZ Domain-Mediated Interactions." Journal of the American Chemical Society, 2013, 135 (12), pp 4580-4583.

As Published: http://dx.doi.org/10.1021/ja309870q

Publisher: American Chemical Society

Persistent URL: http://hdl.handle.net/1721.1/86182

Version: Author's final manuscript: final author's manuscript post peer review, without publisher's formatting or copy editing

Terms of Use: Article is made available in accordance with the publisher's policy and may be subject to US copyright law. Please refer to the publisher's site for terms of use. 


\title{
Caged Mono- and Divalent Ligands for Light-Assisted Dis- ruption of PDZ Domain-Mediated Interactions
}

\author{
Matthieu Sainlos, ${ }^{+,, \S}$ Wendy S. Iskenderian-Epps, ${ }^{\dagger}$ Nelson B. Olivier, ${ }^{\dagger}$ Daniel Choquet, ${ }^{\ddagger, S}$ and Barbara Imperi- \\ ali $^{*,+}$ \\ ${ }^{\dagger}$ Department of Biology and Department of Chemistry, Massachusetts Institute of Technology, Cambridge, MA 02139 (USA). \\ ${ }^{\ddagger}$ University of Bordeaux, IINS, CNRS UMR 5297, F-33000 Bordeaux (France). ${ }^{\circledR}$ CNRS, IINS, UMR 5297, F-33000 Bordeaux \\ (France) \\ Supporting Information Placeholder
}

\begin{abstract}
Herein we report a general method for the light-assisted control of PDZ domain-binding motif interactions with their cognate domains by the incorporation of a photolabile caging group onto the essential C-terminal carboxylate binding determinant of the motif. The strategy is implemented and vaildated for both simple monovalent ligands and biomimetic bivalent ligands, which have recently been establsihed to be powerful tools for acutely perturbing native PDZ domain-dependent interactions in live cells.
\end{abstract}

Understanding the complex dynamics of protein networks at the molecular level requires tools that allow for temporal and spatial control of specific protein-protein interactions. The use of light, as an effective switch to turn on or off biological events in live cells, constitutes a powerful approach owing to its non-invasive nature and potential for high resolution. For instance, photolabile caging groups provide an efficient method for masking critical functionality in small bioactive molecules and protein-binding partners thereby preventing a functional interaction until the liberation of that group through photoactivation. ${ }^{1-3}$ This approach has been successfully applied to masking neurotransmitters, nucleic acids, phosphopeptides, and proteins. ${ }^{2-5}$ Additionally, it has been used to modulate specific protein-protein interactions by exploiting caged variants of molecules that compete with native interactions. ${ }^{5,6}$ In this context, we were interested in developing a chemical caging approach for PDZ (PSD-95/DLG/ZO-1) domainmediated interactions, which constitute an important and abundant protein-protein interaction system in mammals. ${ }^{7}$ Small globular PDZ domains are found in multi-domain repeats or associated with other protein interaction domains and occur principally at cell junctions. In this location, PDZ domains are key players in the assembly and localization of macromolecular complexes involved in signal transduction pathways. ${ }^{8-10}$ These types of interactions play a pivotal role in governing the dynamic localization of ion channels and receptors, particularly when they occur at synaptic junctions. ${ }^{9}$ As such, they have been the focus of numerous studies involving the application of peptide-based ligands to acutely disrupt native interactions and define their functional roles in transient macromolecular complexes. ${ }^{11-13}$ We have recently introduced a series of synthetic biomimetic ligands that efficiently disrupt the synaptic PDZ domain-mediated interactions involved in anchoring glutamate receptors $\left(\mathrm{AMPA}^{12}\right.$ and $\mathrm{NMDA}^{13}$ ) to macromolecular complexes in the post synaptic density in live cells. While these ligands have provided us with valuable insights into these interactions, the challenge of deciphering the various modes of regulation and their functional implications would greatly benefit from new tools that allow spatiotemporal control over these binding events.

Herein we report the design, synthesis and characterization of caged PDZ domain ligands (PDLs) for the photochemical control and study of protein-protein interactions mediated by this family of domains. Indeed, this strategy should provide excellent spatiotemporal resolution to the acute disruption of endogenous PDZ domain binding events by controlling when and where a ligand can bind to its cognate protein partner. Our goals are both to develop a general caging method for PDLs and to implement the approach to the recently reported biomimetic ligands. ${ }^{12,13}$ In order to establish the general strategy and to assess the caging efficiency, we have exploited solvatochromic fluorophores for directly monitoring the interaction of monovalent and bivalent peptide-based ligands and their cognate PDZ domains. ${ }^{14,15}$

As a first step in the design process, we obtained structural evidence that the fluorogenic probes previously described ${ }^{15}$ constituted canonical PDLs, thereby providing a paradigm for this class of protein interaction. Crystallographic analysis of a PDZ domain bound to a prototypic fluorescent ligand established that the binding mode is comparable to that of other previously reported ligands, ${ }^{8,16}$ thus excluding any perturbing role of the fluorophore and validating the use of the probes as representative PDLs (Figure 1 and Figure S1 in the Supporting Information). For the design of efficient caged ligands, we focused on the residues that are conserved within canonical PDZ domain-binding motifs to ensure both disruption of critical interactions and the establishment of a general strategy that could be broadly applied to different domain classes. Structural analyses ${ }^{8,16}$ have consistently revealed that the canonical binding of PDLs involves their C-terminal sequence, typically via the terminal amino acid hydrophobic side chain and carboxylate as well as the residue in the -2 position (Figure 1 and Figure S2). The nature of the peptide ligand residue at the -2 position changes amongst various PDZ domains and is used to distinguish specific domains into classes. ${ }^{17}$ Therefore, amongst the conserved interactions described above, the $\mathrm{C}$-terminal carboxylate constitutes the ideal target for caging, owing to the presence across all classes of PDZ domains, the essentiality in binding and the intrinsic chemical reactivity. Introduction of a photolabile group at this position on a PDL would be anticipated to both abolish key electrostatic interactions involved in binding to the domains and introduce steric hindrance, therefore resulting in significant impairment of interactions with PDZ domains (Figure 1). 

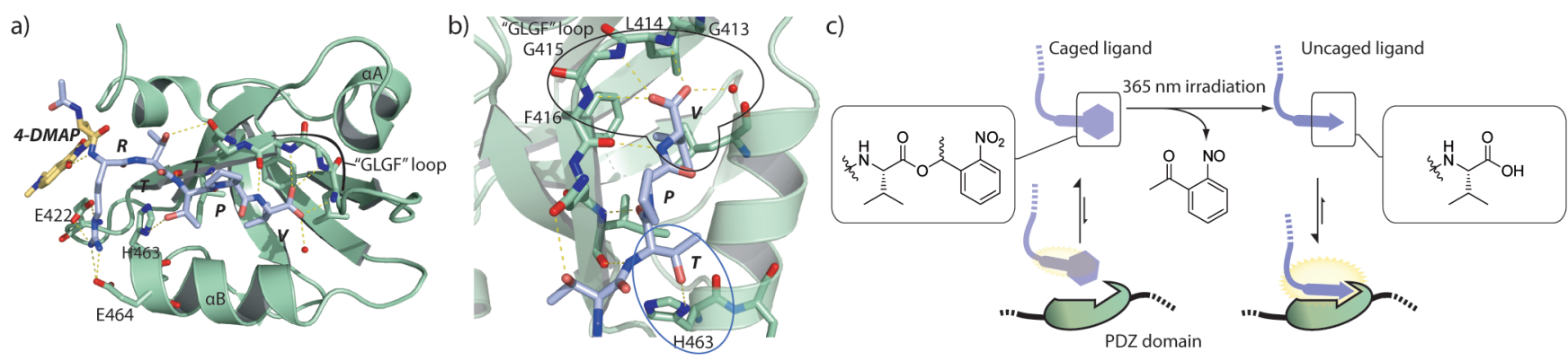

d)
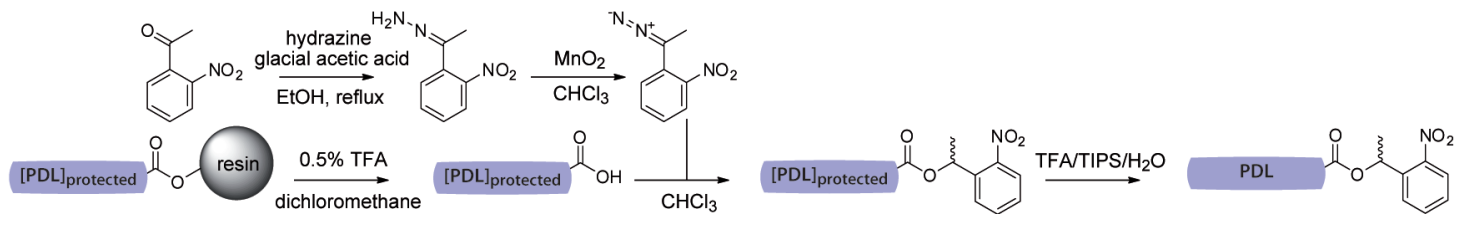

Figure 1. Caged PDL design and synthesis. a) Structure of the fluorescent probe 1 (stick representation in blue color theme with the non-natural amino acid Dab(4-DMAP) in orange) bound to the third PDZ domain of SAP102 in green (PDB: 3JXT). The hydrogen bonds between the ligand and the domain are highlighted in yellow. b) Conserved PDZ domain-ligand interactions. In addition to less specific interactions of the PDL backbone, amino acids at position 0 (circled in black) and -2 (circled in blue) interact strongly and in a conserved manner with the domain surface residues. c) General caging strategy. Incorporation of a caging group such as NPE on the C-terminal carboxylate of a PDL should strongly impair the capacity to bind partner PDZ domains, which can then be recovered, when desired, by photorelease. Application of this strategy to PDZ domain fluorescent reporters allows direct monitoring of the interaction. d) General synthesis of caged PDLs.

The method used to obtain ligands caged at the C-terminal carboxylate was based on the introduction of a photolabile group following solid phase peptide synthesis. This strategy relies on activation of the caging group as a diazoalkane rather than the carboxylate as an activated ester in order to minimize potential epimerization of the terminal amino acid. The diazoalkane approach has been reported for caging phosphate derivatives ${ }^{18}$ and amino acids, ${ }^{19}$ and could be modified for use with peptide-based ligands. We chose the 1-(2-nitrophenyl)ethyl (NPE) caging group for its compatibility with biological applications ${ }^{2}$ and the facile chemical activation process afforded for reaction with the target carboxylates. ${ }^{18,19}$ Peptides were first synthesized by standard Fmoc-based SPPS methods on highly acid-sensitive resin (e.g., 4carboxytrityl linker) and derivatized with the 4dimethylanimophthalimide (4-DMAP) fluorophore ${ }^{20}$ according to previously reported methods. ${ }^{21}$ The resulting peptides were cleaved from the resin with $0.5 \%$ TFA, thus preserving the side-chain protecting groups in order to allow selective coupling of the free C-terminal carboxylate with a diazo-activated NPE group (Figure 1d and Figure S3). The caging strategy was applied to the recently reported probes derived from the $\mathrm{C}$-terminal sequences of Stargazin, GluN2A and GluA1 targeting representative class I PDZ domains from synaptic PSD-95-like proteins (PSD-95, PSD-93, SAP97 and SAP102) and Shank3 (Table 1). ${ }^{15}$

Table 1. Fluorescent peptide-based PDLs.

\begin{tabular}{|c|c|c|c|}
\hline Entry & Origin & Sequence $^{a}$ & Probe for ${ }^{b}$ \\
\hline 1 & Stargazin & 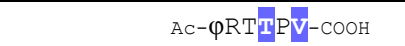 & PLP-3 \\
\hline 2 & Stargazin & Ac-NTAN $\varphi$ RTMV-COOH & PLP-3 \\
\hline 3 & Stargazin & Ac-NTAN $\varphi R T$ TIV-COONPE & n.a. \\
\hline 4 & GluN2A & Ac-NRRVYKK $\lambda$ P $\varphi$ IESDV-COOH & PLP-12 \\
\hline 5 & GluN2A & Ac-NRRVYKK $\lambda P \varphi$ IESDV-COONPE & n.a. \\
\hline 6 & GluA1 & Ac-NRRSG $\mathrm{P} P \varphi \mathrm{GA} \mathrm{\Psi} G \mathrm{\Psi}-\mathrm{COOH}$ & Shank-3 \\
\hline 7 & GluA1 & Ac-NRRS $G \lambda P \varphi$ PAT GI-COONPE & n.a. \\
\hline
\end{tabular}

${ }^{\mathrm{a}} \varphi$ : Dab(4-DMAP); $\lambda$ : norleucine; Ac: acetyl group. Critical residues at positions 0 and -2 and the NPE caging group are highlighted in blue and red respectively. ${ }^{b}$ n.a.: not applicable. PLP-3 and PLP-12 stand respectively for the third and the first two PDZ domains of PSD95-like proteins.
The photolysis of the C-terminal caged peptides was first studied via HPLC by submitting a solution of caged ligand 3 to various durations of exposure to $365 \mathrm{~nm}$ UV light (Figure S4). Under these conditions, the amount of uncaged free acid, $\mathbf{2}$, increased incrementally from 0 to more than $80 \%$ over $300 \mathrm{~s}$ while the caged peptide amount decreased to $5 \%$.

In parallel, the capacity of the caged and uncaged ligands to bind cognate PDZ domains was evaluated by monitoring relative fluorescence increases in comparison to changes observed with non-caged probes (Figure 2 and S5). In the absence of protein, base-line fluorescence levels were similar for caged and non-caged ligands, indicating that the probe fluorescence was not affected by the presence of the NPE group in proximity to the reporter fluorophore (Figure S5). In the presence of the cognate PDZ domain introduction of the caging group clearly resulted in significant loss of fluorescence. Indeed the relative fluorescence increases were generally lower than $12 \%$ of those of the non-caged ligand ( $t=0 \mathrm{~s}$, Figure 2, except for GST-PSD-95-12, see Figure S5). Since we have previously shown a correlation between fluorescence increase and affinity within a given series of ligands for the same PDZ domain, these observations reflect a lower binding affinity of the caged ligand. ${ }^{15}$ Furthermore, exposure of the caged ligands to various durations of $\mathrm{UV}$-irradiation $(t=120$ and $300 \mathrm{~s})$ to release the caging group by photolysis and reveal the free $\mathrm{C}$-terminal carboxylate resulted in the stepwise recovery of the fluorescence signal in presence of PDZ domains. At $t=300 \mathrm{~s}$, all ligands yielded fluorescence increases corresponding to more than $\sim 70 \%$ of the maximum possible increase obtained with uncaged ligands, which is consistent with the uncaging levels observed by HPLC (Figure S4). As controls, UV-irradiation alone did not result in significant photobleaching or increase of fluorescence, validating the use of fluorescence as an efficient method for following the modulation of PDZ domain-mediated interactions.

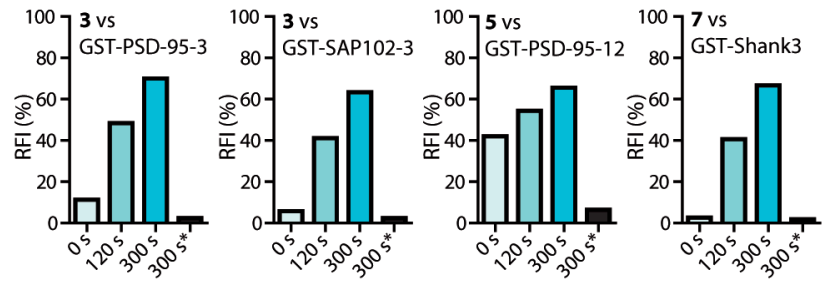


Figure 2. Generation of uncaged ligand by photolysis. Relative fluorescence increase (RFI) of the caged probes in the presence of cognate PDZ domain(s) at increasing durations of irradiation at $365 \mathrm{~nm}$. In each case, the RFI is obtained by comparison to levels of fluorescence obtained with the same amount of the corresponding non-caged probe. The last entry in each graph $\left(300 \mathrm{~s}^{*}\right)$ corresponds to the RFI obtained in the absence of PDZ domain(s) after 300 s irradiation.

Next, the validity of the caging strategy was established by determining the relative binding affinities of the caged and uncaged peptides by fluorescence titration with their respective cognate domains (Table 2 and Figure S6). Under the conditions tested, binding saturation was not reached with the caged variants of the probes at concentrations well above those needed to achieve complete binding with free terminal carboxylate-containing ligands. The dissociation constants of the caged peptides were estimated to be at least 20 -fold weaker than those of the parent peptides. Furthermore, we also observed that the fluorescence signal was much weaker for all of the caged ligands, again confirming the weak affinities and the efficacy of the C-terminal carboxylate caging strategy.

Table 2. Dissociation constants of caged $v$ s non-caged probes for their respective cognate $\mathrm{PDZ}$ domains. ${ }^{\mathrm{a}}$

\begin{tabular}{lllll}
\hline & \multicolumn{2}{l}{ Non-caged ligand } & \multicolumn{2}{l}{ Caged ligand } \\
\hline PDZ domain(s) & Entry & $K_{D}(\mu \mathrm{M})^{\mathrm{b}}$ & Entry & $K_{D}(\mu \mathrm{M})^{\mathrm{b}}$ \\
\hline GST-PSD-95-3 & $\mathbf{2}$ & $1.66 \pm 0.32$ & $\mathbf{3}$ & $37.07 \pm 4.95$ \\
GST-SAP102-3 & $\mathbf{2}$ & $5.45 \pm 0.59$ & $\mathbf{3}$ & $148.4 \pm 82.8$ \\
GST-PSD-95-12 & $\mathbf{4}$ & $1.97 \pm 0.26$ & $\mathbf{5}$ & $82.9 \pm 25.8$ \\
GST-Shank3 & $\mathbf{6}$ & $1.44 \pm 0.30$ & $\mathbf{7}$ & $59.9 \pm 29.6$ \\
\hline
\end{tabular}

${ }^{\mathrm{a}}$ see Figure $\mathrm{S} 7$ for the titration curves. ${ }^{\mathrm{b}} K_{D} \pm$ standard error.

Having assessed the efficiency of C-terminal carboxylate caging in blocking ligand-PDZ domain interactions as well as the light-assisted recovery of the interaction by photorelease of the caging group, we then probed the caged ligands for their capacity to compete against prototypical PDZ domain-mediated interactions upon exposure to light. For this purpose, we compared the effect of non-fluorescent caged and uncaged ligands at disrupting the interaction of a fluorescent probe with its cognate PDZ domain (2 vs GST-PSD-95-3, Figure 3). Consistent with the observed loss of affinity after introduction of the caging group in the absence of irradiation at $365 \mathrm{~nm}$, the addition of a 20 -fold excess of the caged nonfluorescent competing ligand, 9 , led to a minimal perturbation of the interaction with less than $7 \%$ decrease of fluorescence. In parallel, the same concentration of the non-caged version, 8 , reduced the fluorescent signal by more than $50 \%$. However, after UV irradiation and uncaging of ligand $\mathbf{9}$, most of the competing properties of the peptide sequence were recovered as judged by the significant loss of fluorescence comparable to the levels obtained with non-caged ligand (40\%).
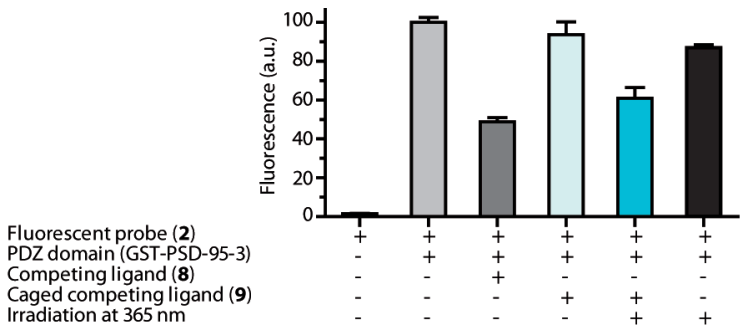

Figure 3. Light-assisted disruption of PDZ domain-mediated interactions. Competing properties of caged and non-caged ligand were estimated by observing disruption of the binding of a fluorescent probe ( 5 $\mu \mathrm{M})$ to its target PDZ domain $(5 \mu \mathrm{M})$. Competing ligands were used in a 20 -fold molar excess.
Application of the same treatment to the probe-PDZ domain pair did reveal a small amount of fluorophore photobleaching, albeit at levels that do not account for the effect observed after photoactivation of the caged competitor. This confirms the light-induced disruption of the probe-PDZ domain interaction.

We have recently demonstrated that a new class of biomimetic ligands, comprising two covalently linked PDZ domain-binding motifs, acutely and specifically disrupts the synaptic stabilization of endogenous glutamate receptors in situations where monovalent ligands proved ineffective. ${ }^{12,13}$ We were therefore motivated to implement the carboxyl caging strategy to develop efficient competitors of PDZ domain-mediated interactions in live cells. In order to take advantage of the validated bivalent biomimetic design, while also maintaining optimal uncaging efficiency (i.e., a single uncaging event required for full recovery of the binding properties, as opposed to a double uncaging if the divalent ligands were symmetrically caged), the original synthetic scheme of the ligand ${ }^{12}$ required a new strategy to allow for the introduction of a single caging group per divalent ligand (Figure 4a). In particular, we note that after on-resin ligation the original synthesis provided a symmetrical ligand dimer, which could not be easily used for introducing a caging group on only one of the C-terminal carboxylates. In order to generate the desired singly caged divalent ligand, we took advantage of the versatility and chemical orthogonality of coppercatalyzed azide-alkyne click chemistry to achieve the ligation of the two forms of the ligand (caged and non-caged) in solution rather than on resin. The resulting mono-caged divalent ligand derived from the Stargazin sequence was evaluated by a competition assay with the tandem PDZ domains of PSD-95 in comparison to both non-caged divalent and monovalent ligands (Figure 4b). The affinity constants confirmed that the insertion of a single caging group on a divalent ligand resulted in a behavior comparable to that of the corresponding monovalent ligand $\left(K_{I} 0.49 \pm 0.01,14.2 \pm 3.1\right.$ and $17.9 \pm 0.7 \mu \mathrm{M}$ for the non-caged divalent, 11, monovalent, 8, and mono-caged divalent ligand, 10, respectively). In light of our previous studies, ${ }^{12,13}$ it is evident that the caging and photorelease of the masking group provides a simple method to control the activity of these potent ligands with respect to their capacity to acutely disrupt PDZ domain-mediated anchoring of the glutamate receptors at the synapse. These results also indicate that the general C-terminal caging approach as a method to control PDZ domain-ligand binding can be extended to more complex systems.
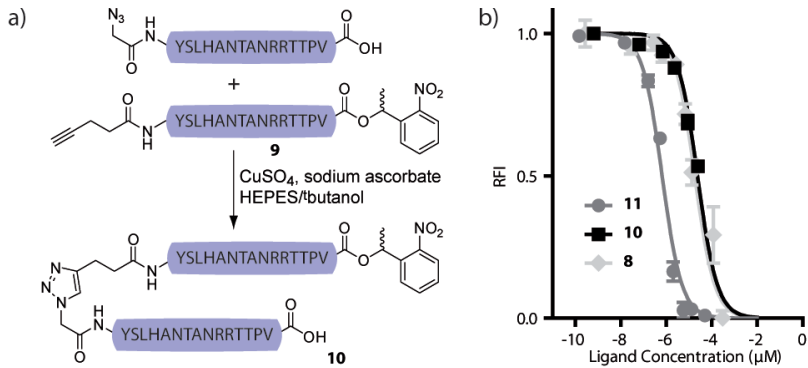

Figure 4. a) Synthesis of mono-caged divalent PDL (see Figure S7 for details). b) Fluorescence-based competition assay. The fluorescence signal resulting from the interaction of GST-PSD-95-12 and probe 2 was monitored as increasing concentrations of various non-fluorescent ligands were added (8, monovalent; 10, mono-caged divalent; 11, divalent).

In summary, we have described a general and versatile method to control the binding of a PDL to its cognate PDZ domains using photoactivation. By introducing a caging group on the critical C-terminal carboxylate of a ligand binding motif, interactions with targeted PDZ domains can be strongly impaired until a photorelease event is triggered. Considering the prevalence of $\mathrm{C}$-terminal binding motifs for PDLs over less common internal sequences, ${ }^{22}$ the approach should be 
generally applicable to most PDZ domain-mediated interactions. It is also noteworthy that in a complementary approach photoswitchable cyclic peptides were recently reported for non-canonical internal binding motifs. ${ }^{23}$ Importantly, the caging method can be applied to more sophisticated bivalent ligand designs and, in this case, we have demonstrated that a single caging group is sufficient to confer the ligands with tailored binding properties revealed by a single uncaging event. Together, these studies provides a new set of tools characterized by high spatiotemporal resolution that can be applied to study transient and localized biological events involving PDZ domain-mediated interactions.

\section{ASSOCIATED CONTENT}

\section{Supporting Information}

Supporting figures and experimental methods. This material is available free of charge via the Internet at http://pubs.acs.org.

\section{AUTHOR INFORMATION}

\section{Corresponding Author}

imper@mit.edu

\section{ACKNOWLEDGMENT}

This research was supported by NSF CHE-0414243 (to B.I.), the Cell Migration Consortium (GM064346), the Marie Curie postdoctoral Fellowship (PICK-CPP, M.S.) and the ANR (ChemTraffic, M.S., D.C.). We are grateful to the staff at the NSLS beamline X6A for access via the General User program.

\section{REFERENCES}

(1) Adams, S. R.; Tsien, R. Y. Annu. Rev. Physiol. 1993, 55, 755-84; Brieke, C.; Rohrbach, F.; Gottschalk, A.; Mayer, G.; Heckel, A. Angew. Chem. 2012, 51, 8446-76.

(2) Ellis-Davies, G. C. Nat. Methods 2007, 4, 619-28.

(3) Mayer, G.; Heckel, A. Angew. Chem. 2006, 45, 4900-4921.

(4) Goguen, B. N.; Hoffman, B. D.; Sellers, J. R.; Schwartz, M. A.; Imperiali, B. Angew. Chem. 2011, 50, 5667-70; Lee, H. M.; Larson, D. R.; Lawrence, D. S. ACS Chem. Biol. 2009, 4, 409-27; Riggsbee, C. W.; Deiters, A. Trends Biotechnol. 2010, 28, 468-75; Banghart, M. R.; Sabatini, B. L. Neuron 2012, 73, 249-59.

(5) Nguyen, A.; Rothman, D. M.; Stehn, J.; Imperiali, B.; Yaffe, M. B. Nat. Biotechnol. 2004, 22, 993-1000.

(6) Humphrey, D.; Rajfur, Z.; Vazquez, M. E.; Scheswohl, D.; Schaller, M. D.; Jacobson, K.; Imperiali, B. J. Biol. Chem. 2005, 280, 22091-101; Kuner, T.; Li, Y.; Gee, K. R.; Bonewald, L. F.; Augustine, G. J. Proc. Natl. Acad. Sci. U.S.A. 2008, 105, 347-52.

(7) Bhattacharyya, R. P.; Remenyi, A.; Yeh, B. J.; Lim, W. A. Annu. Rev. Biochem. 2006, 75, 681-706; Luck, K.; Charbonnier, S.; Trave, G. FEBS Lett. 2012, 586, 2648-61.

(8) Hung, A. Y.; Sheng, M. J. Biol. Chem. 2002, 277, 5699-5702.

(9) Kim, E. J.; Sheng, M. Nat. Rev. Neurosci. 2004, 5, 771-781.

(10) Nourry, C.; Grant, S. G.; Borg, J. P. Sci. STKE 2003, 2003, RE7; Feng, W.; Zhang, M. J. Nat. Rev. Neurosci. 2009, 10, 87-99.

(11) Aarts, M.; Liu, Y.; Liu, L.; Besshoh, S.; Arundine, M.; Gurd, J. W.; Wang, Y. T.; Salter, M. W.; Tymianski, M. Science 2002, 298, 846-850; Gerges, N. Z.; Backos, D. S.; Rupasinghe, C. N.; Spaller, M. R.; Esteban, J. A. EMBO J 2006, 25, 1623-34; Bertaso, F.; Zhang, C.; Scheschonka, A.; de Bock, F.; Fontanaud, P.; Marin, P.; Huganir, R. L.; Betz, H.; Bockaert, J.; Fagni, L.; LernerNatoli, M. Nat. Neurosci. 2008, 11, 940-948.

(12) Sainlos, M.; Tigaret, C.; Poujol, C.; Olivier, N. B.; Bard, L.; Breillat, C.; Thiolon, K.; Choquet, D.; Imperiali, B. Nat. Chem. Biol. 2011, 7, 81-91.

(13) Bard, L.; Sainlos, M.; Bouchet, D.; Cousins, S.; Mikasova, L.; Breillat, C.; Stephenson, F. A.; Imperiali, B.; Choquet, D.; Groc, L. Proc. Natl. Acad. Sci. U.S.A. 2010, 107, 19561-19566.

(14) Loving, G. S.; Sainlos, M.; Imperiali, B. Trends Biotechnol. 2010, 28, $73-83$ $131,6680-6682$

(16) Cabral, J. H. M.; Petosa, C.; Sutcliffe, M. J.; Raza, S.; Byron, O.; Poy, F.; Marfatia, S. M.; Chishti, A. H.; Liddington, R. C. Nature 1996, 382, 649-652; Doyle, D. A.; Lee, A.; Lewis, J.; Kim, E.; Sheng, M.; MacKinnon, R. Cell 1996 $85,1067-1076$.

(17) Songyang, Z.; Fanning, A. S.; Fu, C.; Xu, J.; Marfatia, S. M.; Chishti, A. H.; Crompton, A.; Chan, A. C.; Anderson, J. M.; Cantley, L. C. Science 1997, $275,73-77$

(18) Walker, J. W.; Reid, G. P.; McCray, J. A.; Trentham, D. R. J. Am. Chem. Soc. 1988, 110, 7170-7177.

(19) Wilcox, M.; Viola, R. W.; Johnson, K. W.; Billington, A. P.; Carpenter, B. K.; McCray, J. A.; Guzikowski, A. P.; Hess, G. P. J. Org. Chem. 1990, 55, 1585-1589.

(20) Vazquez, M. E.; Rothman, D. M.; Imperiali, B. Org. Biomol. Chem. 2004, 2, 1965-1966.

(21) Sainlos, M.; Imperiali, B. Nat. Protoc. 2007, 2, 3219-3225; Sainlos, M.; Imperiali, B. Nat. Protoc. 2007, 2, 3201-3209.

(22) Ivarsson, Y. FEBS Lett. 2012, 586, 2638-47.

(23) Hoppmann, C.; Schmieder, P.; Domaing, P.; Vogelreiter, G.; Eichhorst, J.; Wiesner, B.; Morano, I.; Ruck-Braun, K.; Beyermann, M. Angew. Chem. 2011, 50, 7699-702. 


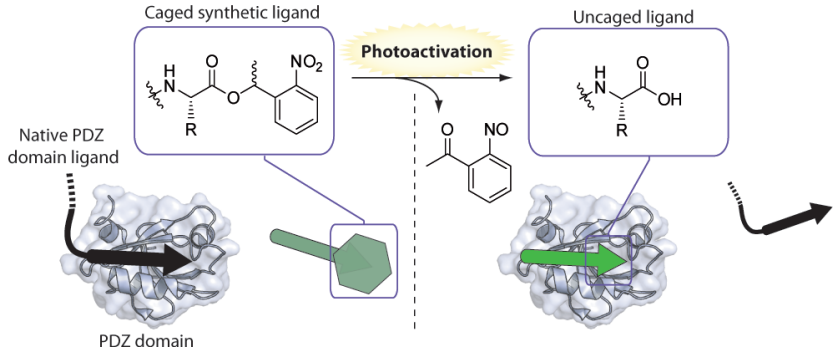




\title{
Supporting Information for
}

\section{Caged Mono- and Divalent Ligands for Light-Assisted Disruption of PDZ Domain-Mediated Interactions}

\author{
Matthieu Sainlos, ${ }^{\dagger, \ddagger, \S}$ Wendy S. Iskenderian-Epps, ${ }^{\dagger}$ Nelson B. Olivier, ${ }^{\dagger}$ \\ Daniel Choquet, ${ }^{\ddagger}$, and Barbara Imperiali ${ }^{*}, \dagger$ \\ ${ }^{\dagger}$ Department of Chemistry and Department of Biology, Massachusetts Institute of \\ Technology, Cambridge, MA 02139 (USA). ${ }^{\ddagger}$ University of Bordeaux, Interdisciplinary \\ Institute for Neuroscience, UMR 5297, F-3300o, Bordeaux (France). ${ }^{\S} \mathrm{CNRS}$, \\ Interdisciplinary Institute for Neuroscience, UMR 5297, F-3300o, Bordeaux (France).
}

*To whom correspondence should be addressed. Email: imper@mit.edu

\section{Table of Contents}

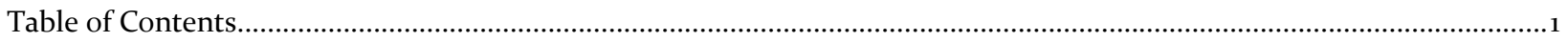

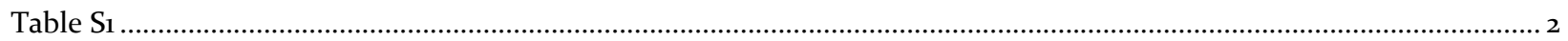

Table S2

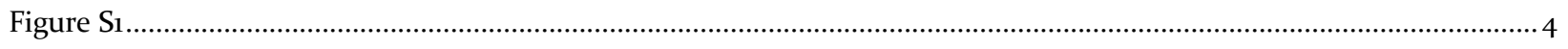

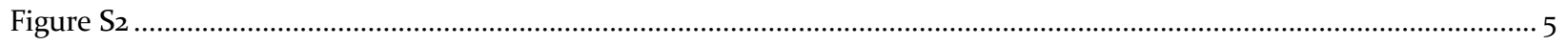

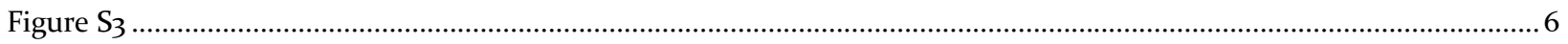

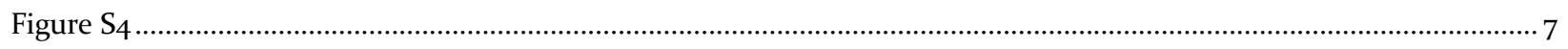

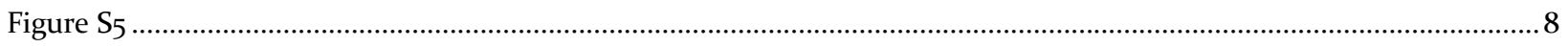

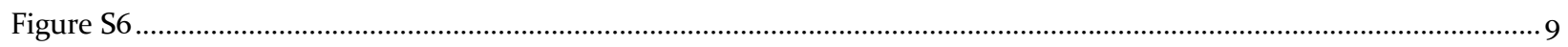

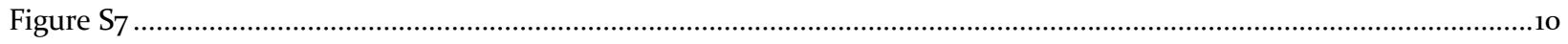

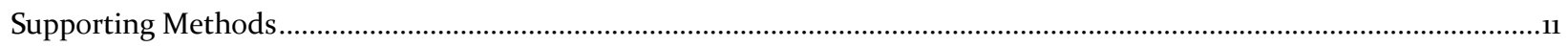

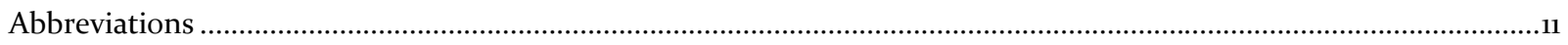

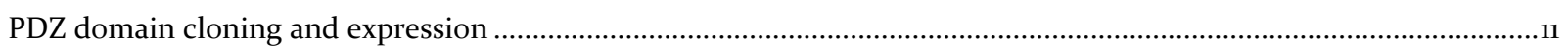

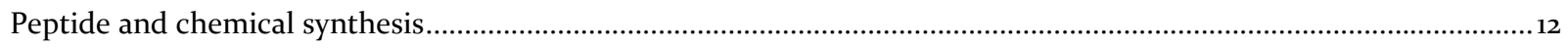

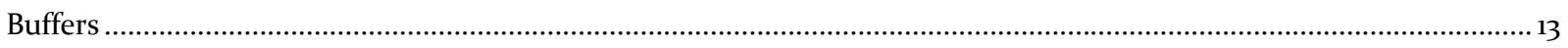

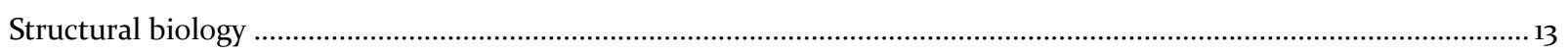

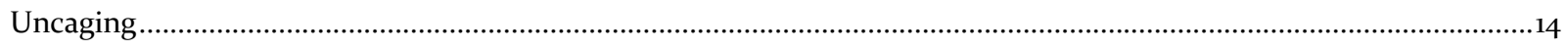

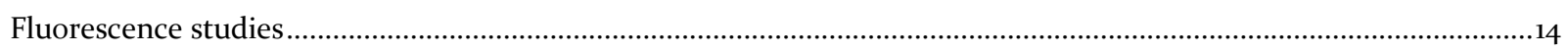

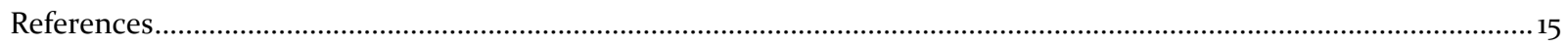




\section{Table Si}

\begin{tabular}{|c|c|c|c|c|c|c|}
\hline Entry & Ligand origin & PDZ domain-binding motif sequence ${ }^{[a]}$ & $t_{R}{ }^{[b]}$ & Formula $(\mathrm{M}+\mathrm{H})^{+}$ & $(\mathrm{M}+\mathrm{H})^{+}$calculated & $\mathrm{m} /$ z observed $^{[c]}$ \\
\hline 1 & Stargazin & Ас- $\phi \quad \mathrm{RT} P \mathrm{PV}-\mathrm{COOH}$ & 26.0 & $\mathrm{C}_{40} \mathrm{H}_{62} \mathrm{~N}_{11} \mathrm{O}_{12}$ & 888.9 & 888.5 \\
\hline 2 & Stargazin & Ac-NTANф RTIPV-соон & 23.9 & $\mathrm{C}_{55} \mathrm{H}_{86} \mathrm{~N}_{17} \mathrm{O}_{19}$ & 1289.4 & 1288.6 \\
\hline 3 & Stargazin & Ac-NTAN $\phi$ RTMPV-COONPE & 31.8 & $\mathrm{C}_{63} \mathrm{H}_{93} \mathrm{~N}_{18} \mathrm{O}_{21}$ & 1438.5 & $1438.9\left(^{+}\right)^{*}$ \\
\hline 4 & GluN2A & Ac-NRRVY KK $\lambda P \phi \quad$ IESDV- & 25.9 & $\mathrm{C}_{92} \mathrm{H}_{147} \mathrm{~N}_{26} \mathrm{O}_{26}$ & 2033.3 & 2033.7 \\
\hline 5 & GluN2A & Ac-NRRVY KK $\lambda \mathrm{P} \phi \quad$ IESDV-COONPE & 31.5 & $\mathrm{C}_{100} \mathrm{H}_{154} \mathrm{~N}_{27} \mathrm{O}_{28}$ & 2182.5 & $1091.8\left(^{(2+}\right) / 728.2\left({ }^{3+}\right)^{*}$ \\
\hline 6 & GluA1 & Ас-NRR $\mathrm{SG} \lambda \mathrm{P} \phi \quad \mathrm{GA} \boldsymbol{I} \mathrm{G}-\mathrm{-}$ & 26.9 & $\mathrm{C}_{65} \mathrm{H}_{105} \mathrm{~N}_{22} \mathrm{O}_{20}$ & 1514.7 & 1513.7 \\
\hline 7 & GluA1 & Ac-NRR $\mathrm{SG} \lambda \mathrm{P} \phi \quad \mathrm{GAT} \mathrm{G}$-COONPE & 31.9 & $\mathrm{C}_{73} \mathrm{H}_{112} \mathrm{~N}_{23} \mathrm{O}_{22}$ & 1663.8 & $832.1\left({ }^{2+}\right)^{*}$ \\
\hline 8 & Stargazin & Ac-YSLHA NTANR RTTP $\overline{\mathbf{V}}-\mathrm{COOH}$ & 21.6 & $\mathrm{C}_{74} \mathrm{H}_{120} \mathrm{~N}_{25} \mathrm{O}_{24}$ & 1743.9 & 1742.8 \\
\hline 9 & Stargazin & Alk-YSLHA NTANR RTIPV-COONPE & 29.6 & $\mathrm{C}_{85} \mathrm{H}_{129} \mathrm{~N}_{26} \mathrm{O}_{26}$ & 1931.1 & 1930.0 \\
\hline 10 & Stargazin & -YSLHA NTANR RTTPV-COOX & 28.7 & $\mathrm{C}_{159} \mathrm{H}_{247} \mathrm{~N}_{54} \mathrm{O}_{50}$ & 3714.9 & 3713.5 \\
\hline 11 & Stargazin & -YSLHA NTANR RTIPV- & 34.9 & $\mathrm{C}_{151} \mathrm{H}_{240} \mathrm{~N}_{53} \mathrm{O}_{48}$ & 3565.9 & 3565.1 \\
\hline
\end{tabular}

Peptide-based ligand sequences and characterization. [a] $\varphi$ : Dab(4-DMAP). $\lambda$ : Norleucine. Ac-: acetyl group. Alk-: pentynoyl group. Critical residues at positions o and -2 are highlighted (green for the common residues found in PSD95, SAP102 and Shank3 ligands). The NPE caging group is highlighted in red and black lettering. For entries 6 and 7 , the N-terminal -NRR- motif was added to improve solubility. For the series of non-fluorescent ligands derived from the Stargazin sequence (8-11) a tyrosine residue -in purple in the table- was incorporated at the N-terminal end of the sequence for quantification purposes. Entries 10 and $\mathbf{1 1}$ correspond to divalent ligands, for ligand $\mathbf{1 0}, \mathrm{X}$ stands for $\mathrm{H}$ and NPE. Refer to supplementary figures $\mathrm{S}_{3}$ and $\mathrm{S}_{4}$ for details on the structures. [b] $t_{\mathrm{R}}$ : retention time. Purity was assessed by analytical reverse phase HPLC (YMC C18, ODS-A 5/120, 250×4.6 mm) using a standard gradient ( $5 \%$ acetonitrile containing $0.1 \%$ TFA for $5 \mathrm{~min}$ followed by $5-95 \%$ acetonitrile containing $0.1 \%$ TFA over $50 \mathrm{~min}$ in water containing $0.1 \%$ TFA at a flow rate of $\left.1 \mathrm{~mL} \cdot \mathrm{min}^{-1}\right)$. All of the peptide-based ligands were more than $95 \%$ pure as judged by analytical HPLC. [c] The identities of the peptide-based ligands were confirmed either by MALDI-TOF mass spectroscopy (PerSeptive Biosystems Voyager) using DHB as a matrix in linear or reflector mode or by ESI when indicated with the asterisk (used for the caged ligands, as the laser desorption in MALDI results in significant uncaging). When using ESI, the detected ions are indicated by $\left(^{+}\right)$for $(\mathrm{M}+\mathrm{H})^{+}$, by $\left({ }^{2+}\right)$ for $(\mathrm{M}+2 \mathrm{H})^{2+}$, or $\left(^{(+)}\right.$for $(\mathrm{M}+3 \mathrm{H})^{3+}$. The observed masses are consistent with the calculated masses of the desired products. 
Table S2

Data collection and refinement statistics (molecular replacement)

\begin{tabular}{|c|c|}
\hline & 3JXT \\
\hline \multicolumn{2}{|l|}{ Data collection } \\
\hline Space group & $\mathrm{P} 2_{1} 2_{1} 2_{1}$ \\
\hline \multicolumn{2}{|l|}{ Cell dimensions } \\
\hline$a, b, c(\AA)$ & $49.6,54.2,86.0$ \\
\hline$\alpha, \beta, \gamma\left(^{\circ}\right)$ & $90,90,90$ \\
\hline Resolution $(\AA)^{\mathrm{a}}$ & $50-1.5\left(1.55^{-1.50}\right)$ \\
\hline$R_{\text {merge }}^{\mathrm{a}, \mathrm{b}}$ & $0.061(0.24)$ \\
\hline$I / \sigma I^{\mathrm{a}}$ & $82.19(6.94)$ \\
\hline Completeness (\%) ${ }^{\mathrm{a}}$ & $99.8(100)$ \\
\hline Redundancy $^{\mathrm{a}}$ & $7.2(7.1)$ \\
\hline \multicolumn{2}{|l|}{ Refinement } \\
\hline Resolution $(\AA ̊)$ & $45 \cdot 9^{-1.50}$ \\
\hline Unique reflections & 35869 \\
\hline$R_{\text {work }} / R_{\text {free }}{ }^{c}$ & $0.185 / 0.214$ \\
\hline \multicolumn{2}{|l|}{ No. atoms } \\
\hline Protein & 1549 \\
\hline Ligand/ion & 40 \\
\hline Solvant & 344 \\
\hline \multicolumn{2}{|l|}{$B$-values } \\
\hline Protein & $13 \cdot 4$ \\
\hline Ligand/ion & 14.1 \\
\hline Solvant & 31.6 \\
\hline \multicolumn{2}{|l|}{ R.m.s. deviations } \\
\hline Bond lengths $(\AA ̊)$ & 0.004 \\
\hline Bond angles $\left(^{\circ}\right)$ & 1.289 \\
\hline
\end{tabular}




\section{Figure S1}

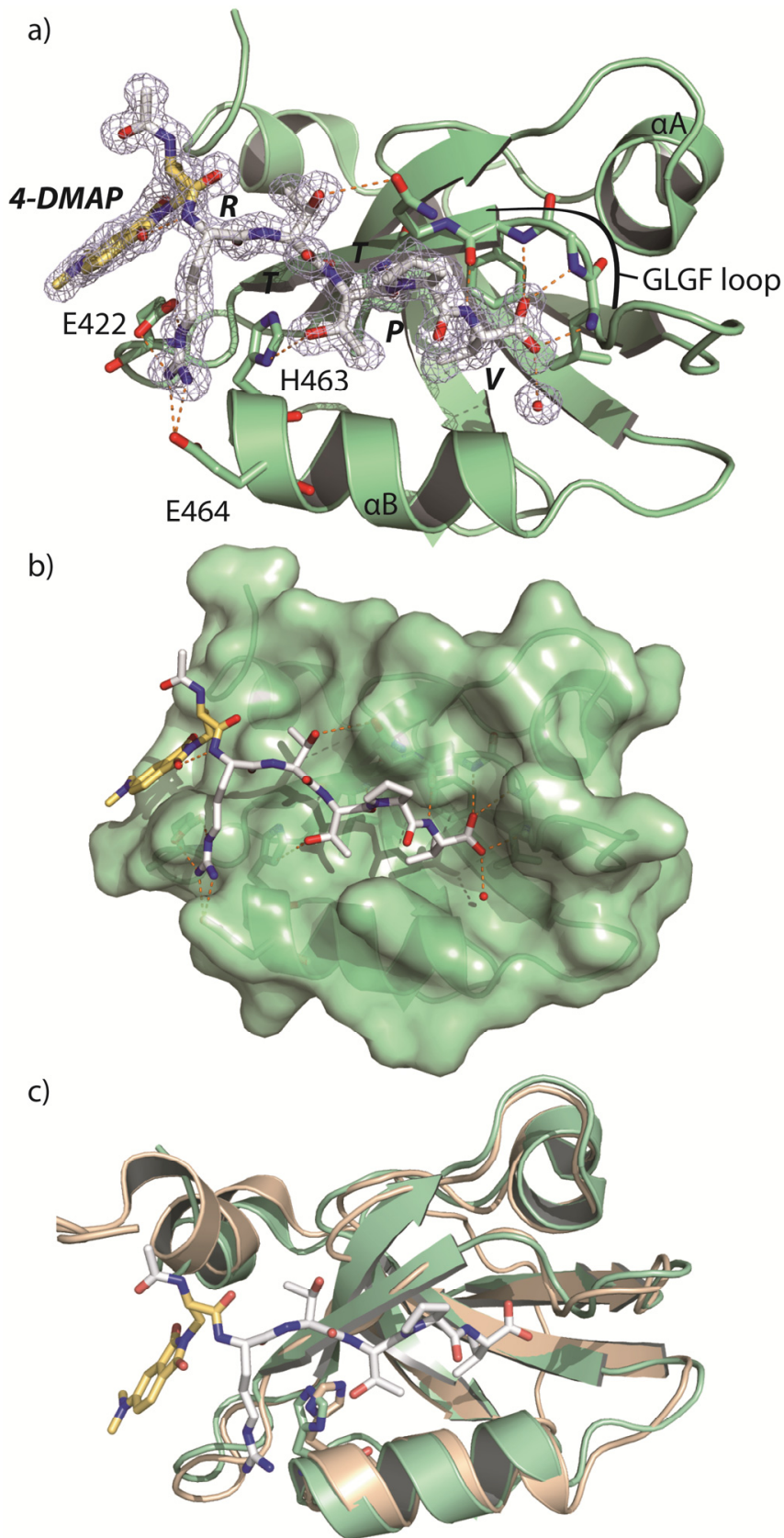

Fluorescent probe bound to SAP1oz third PDZ domain (PDB: 3JXT). Stick representation of 1 (white color theme with the non-natural amino acid Dab(4-DMAP) in orange) in complex with SAP1o2-3 (green color theme). a) Electron density ( 2 Fo-Fc, $\sigma=1 \AA$ ) of probe 1. The conserved canonical interactions -involving the GLGF loop and the C-terminal carboxylate of the ligand via multiple hydrogen bonds, the side chain of the C-terminal Val residue in the domain binding groove hydrophobic pocket, and His463 with Thr-2 of the ligand via a hydrogen bond- can all be observed in the obtained structure. Additional interactions can also be noted such as the stabilization of Arg-4 by formation of salt bridges with Glu422 and Glu463 (which appears to be a common feature of the third PDZ domain of synaptic PSD-95like MAGUKs with conservation of the two Glu residues on the domain and of a basic side chain at the -4 position of ligands, see other structures in Supporting Figure S2) and interactions of the domain with the ligand peptide backbone. b) Surface representation of the PDZ domain illustrating ligand positions that would be sensitive to the insertion of a caging group. c) Alignment of the solved structure to an NMR model of the third PDZ domain of SAP1O2 (human, PDB: ${ }_{1} \mathrm{UM}_{7}$, r.m.s.d. = o.891 $\AA$, salmon color theme). 


\section{Figure S2}

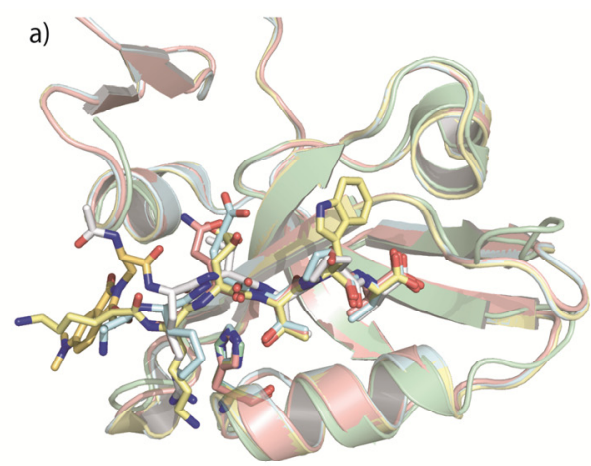

b)
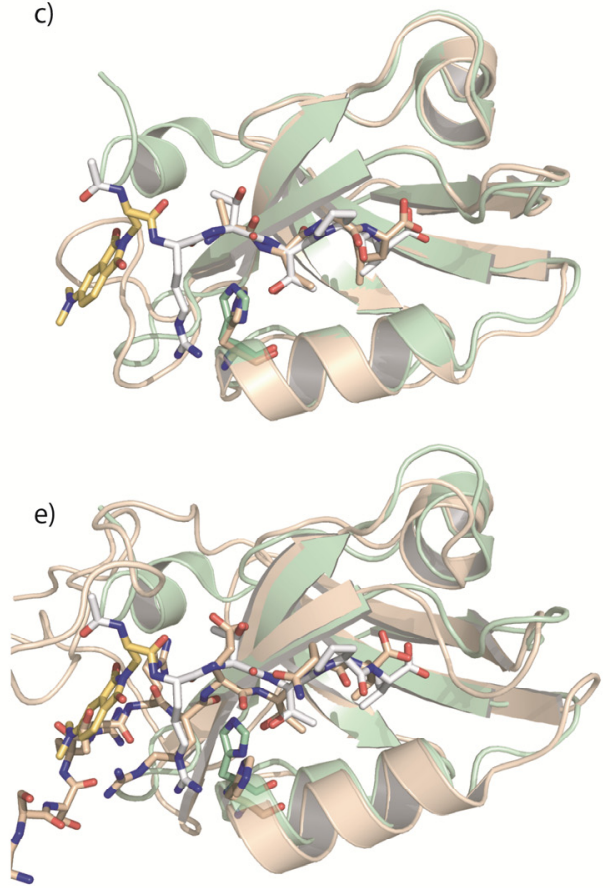

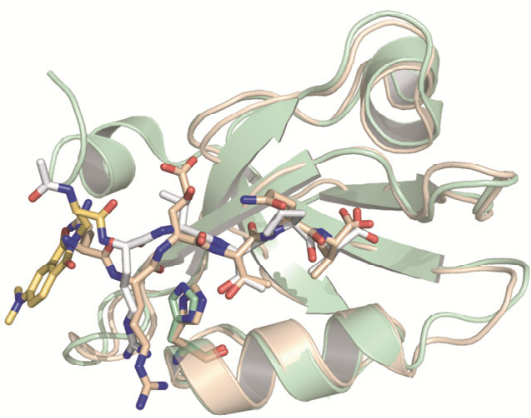

d)

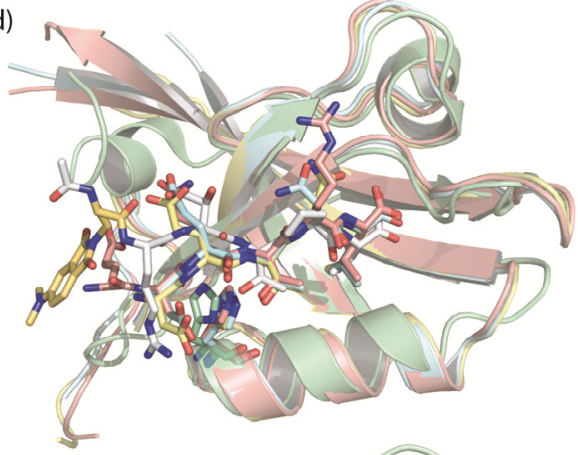

f)

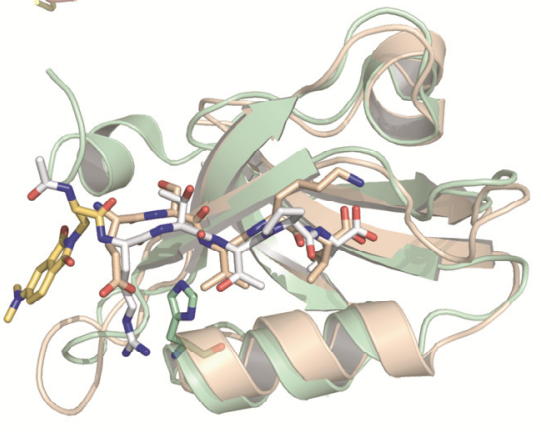

Fluorescent PDZ domain probes as a paradigm of PDZ domain ligand. a)-f) Alignments of the fluorescent probe 1 bound to the third PDZ domain of SAP102 (PDB: 3JXT) to various PDZ domains. Stick representation of ligands and cartoon representation of PDZ domains with a stick representation of the conserved histidine residue for class I PDZ domains. For a)-f), $\mathbf{1}$ is represented in a white color theme with the non-natural amino acid Dab(4-DMAP) in orange and SAP102-3 with a green color theme. a) Alignment of the solved structure to structures of the ligand-bound third PDZ domain of PSD-95 (PDB: 1TP3, ligand: KKETPV, r.m.s.d. = o.499 Å, cyan color theme; PDB: 1TP5, ligand: KKETWV, r.m.s.d. = $0.472 \AA$, yellow color theme; PDB: 1 BE9, ligand: KQTSV, r.m.s.d. = $0.515 \AA$, salmon color theme). b) Alignment of the solved structure to a structure of the ligand-bound third PDZ domain of SAP97 (PDB: 2IoI, ligand: RRETQV, r.m.s.d. $=0.578 \AA$, wheat color theme). c) Alignment of the solved structure to a structure of the ligand-bound second PDZ domain of SAP97 (PDB: 2AWW, ligand: ATGL, r.m.s.d. = o.491 Å, grey color theme). d) Alignment of the solved structure to structures of the ligand-bound PDZ domain of Shankı (PDB: 3QJM, ligand: DETNL, r.m.s.d. = 1.611 Å, cyan color theme; PDB: $3 \mathrm{QJN}$, ligand: DETNL, r.m.s.d. = 1.815 $\AA$, yellow color theme; PDB: ${ }_{1}{ }_{3} \mathrm{P}$, ligand: EAQTRL, r.m.s.d. = 1.608 $\AA$, salmon color theme). e) Alignment of the solved structure to a structure of the ligand-bound first PDZ domain of MAGI-1 (PDB: 2KPL, ligand: RSSRTRRETQV, r.m.s.d. = 1.561 Å, wheat color theme). f) Alignment of the solved structure to a structure of the ligand-bound class II PDZ domain of PICK1 (PDB: 2PKU, ligand: ESVKI, r.m.s.d. = 1.o86 Å, wheat color theme). 


\section{Figure $\mathbf{S}_{3}$}
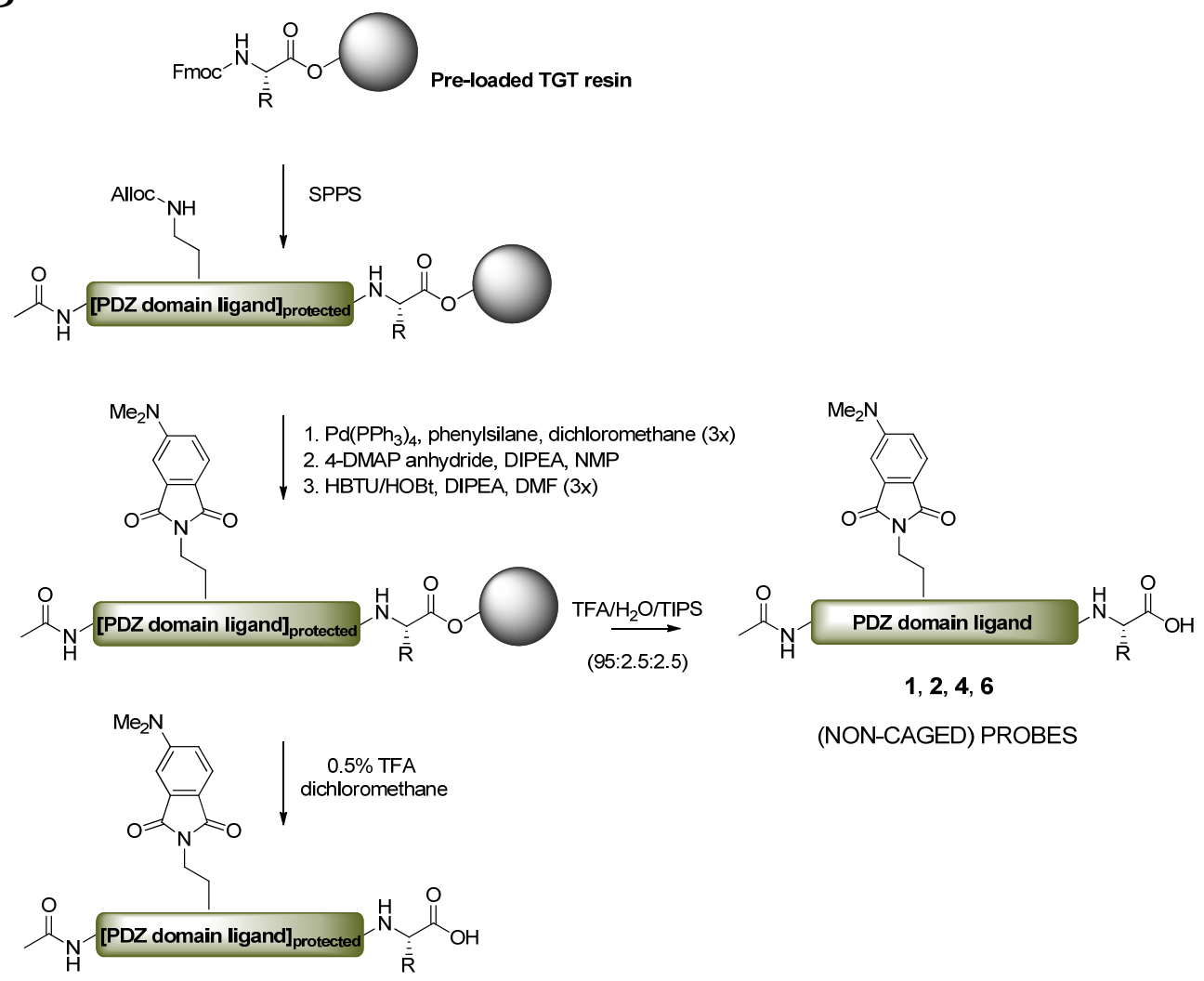

(NON-CAGED) PROBES
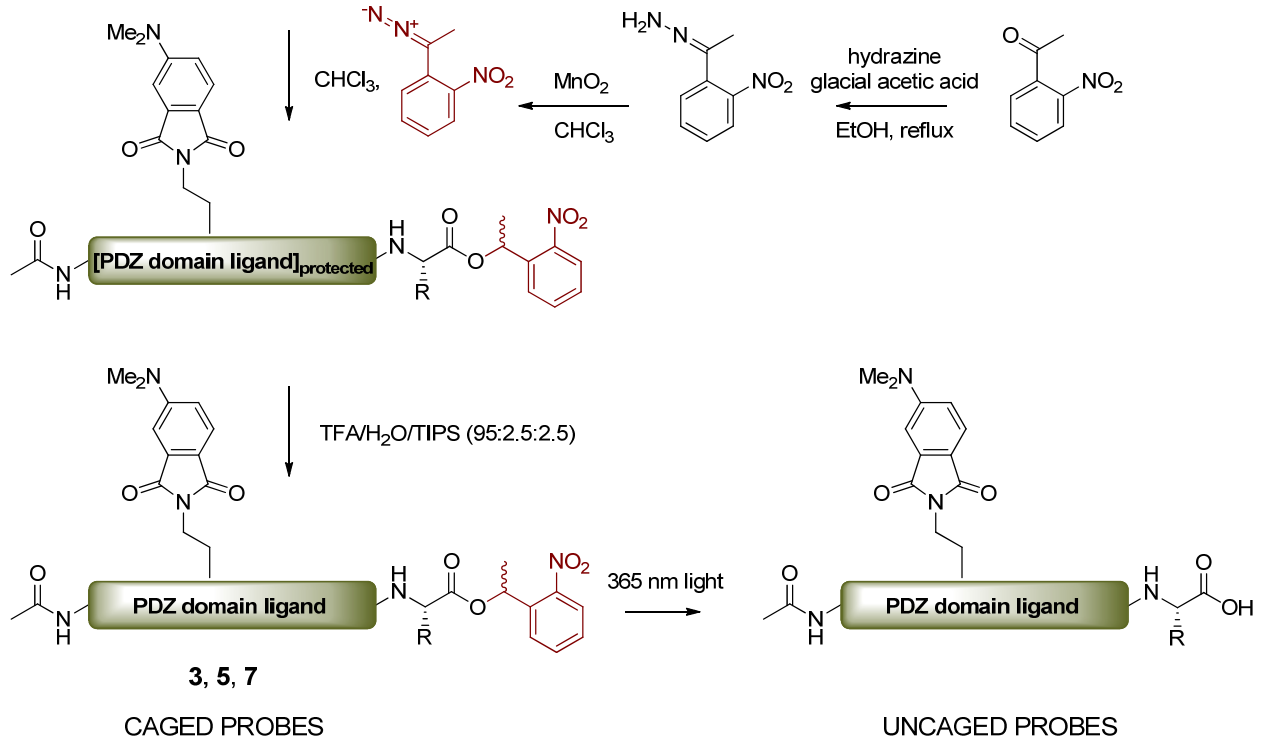

Detailed synthesis of caged and non-caged fluorescent probes (1-7). For 1, 2, 3, 4, and 5, R corresponds to the $i$ propyl group of the valine side chain, while for $\mathbf{6}$ and 7 , R' corresponds to the $i$-butyl group of the leucine side chain. 


\section{Figure $\mathrm{S}_{4}$}

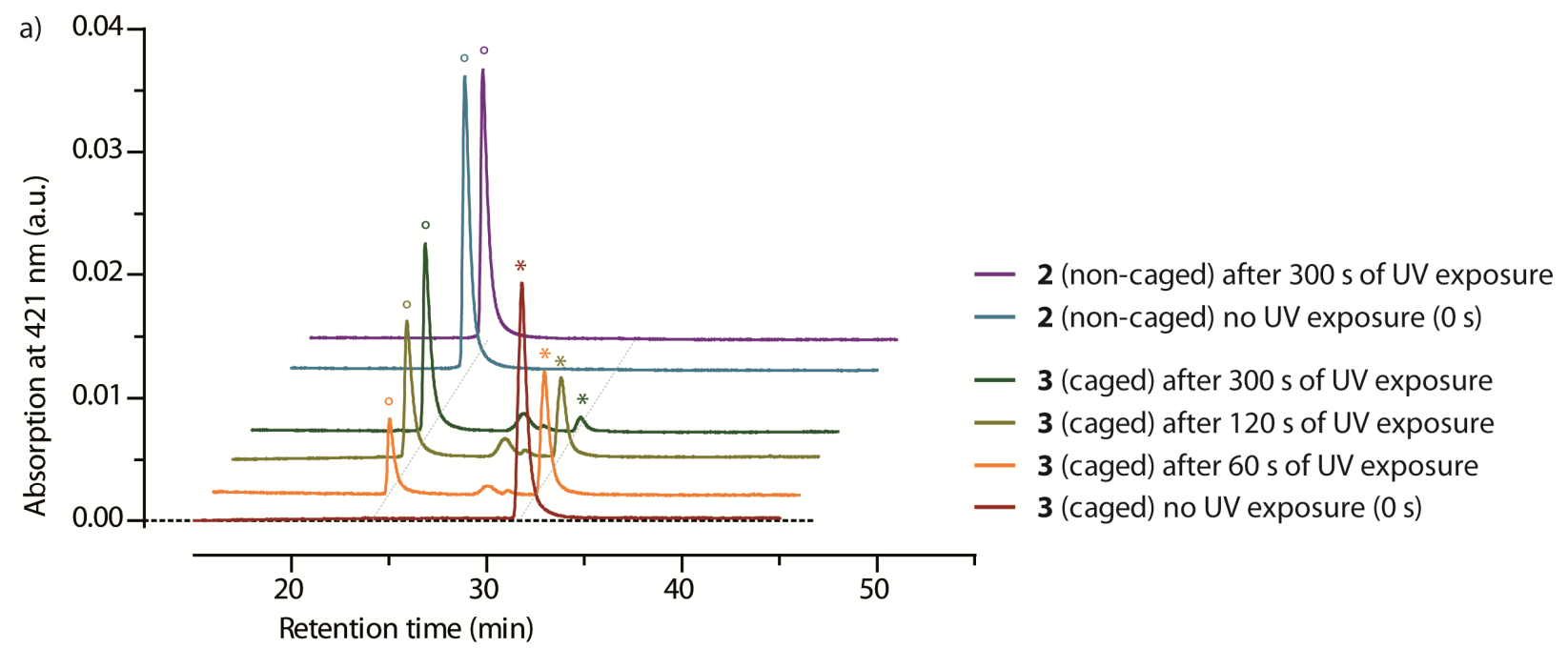

b)

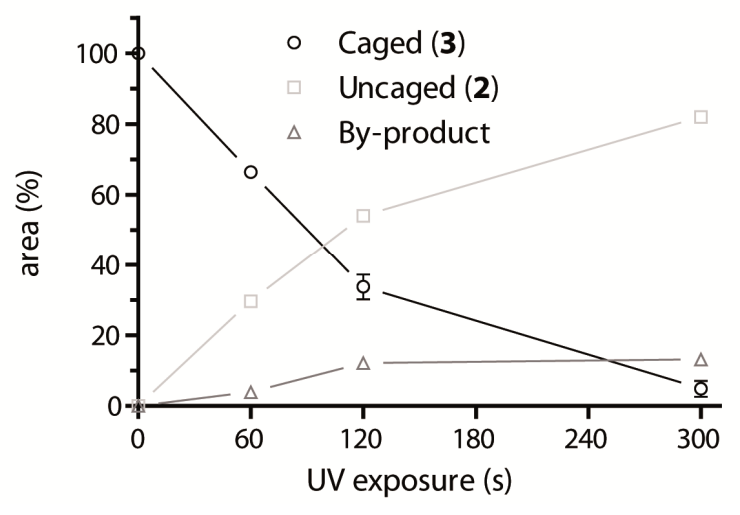

Time course of caged peptide photorelease monitored by RP-HPLC. A solution of the caged peptide 3 (20 $\mu \mathrm{M})$ was submitted to various durations of UV irradiation exposure $(365 \mathrm{~nm})$. The resulting products were analysed and quantified by RP-HPLC at $421 \mathrm{~nm}$. a) Comparison of HPLC traces at $421 \mathrm{~nm}$. The caged starting material (3) is indicated with a star whereas the final expected uncaged product is annotated with a circle. Despite the presence of DTT as a scavenger, we observed the formation of $10 \%$ (or less) minor by-products that could not be identified by mass spectrometry, at intermediate retention times and with a similar profile at 421 and $228 \mathrm{~nm}$. Control reactions under similar conditions with the non-caged probe 2 are not affected by UV irradiation suggesting that that the by-products from caged peptide photolysis are associated with side reactions involving the NPE caging group. b) Quantification of caged and uncaged species for the corresponding HPLC traces. 


\section{Figure $S_{5}$}

a)

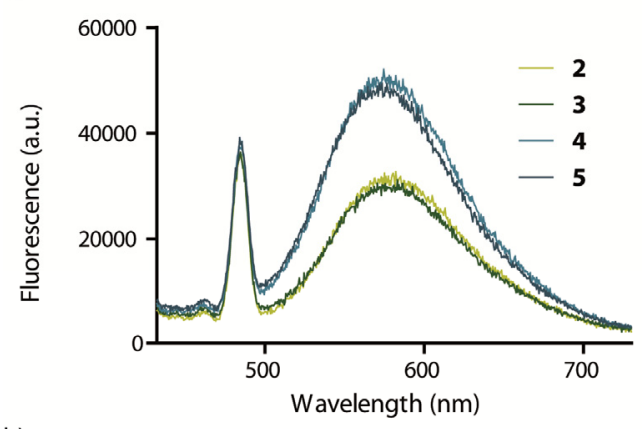

b)
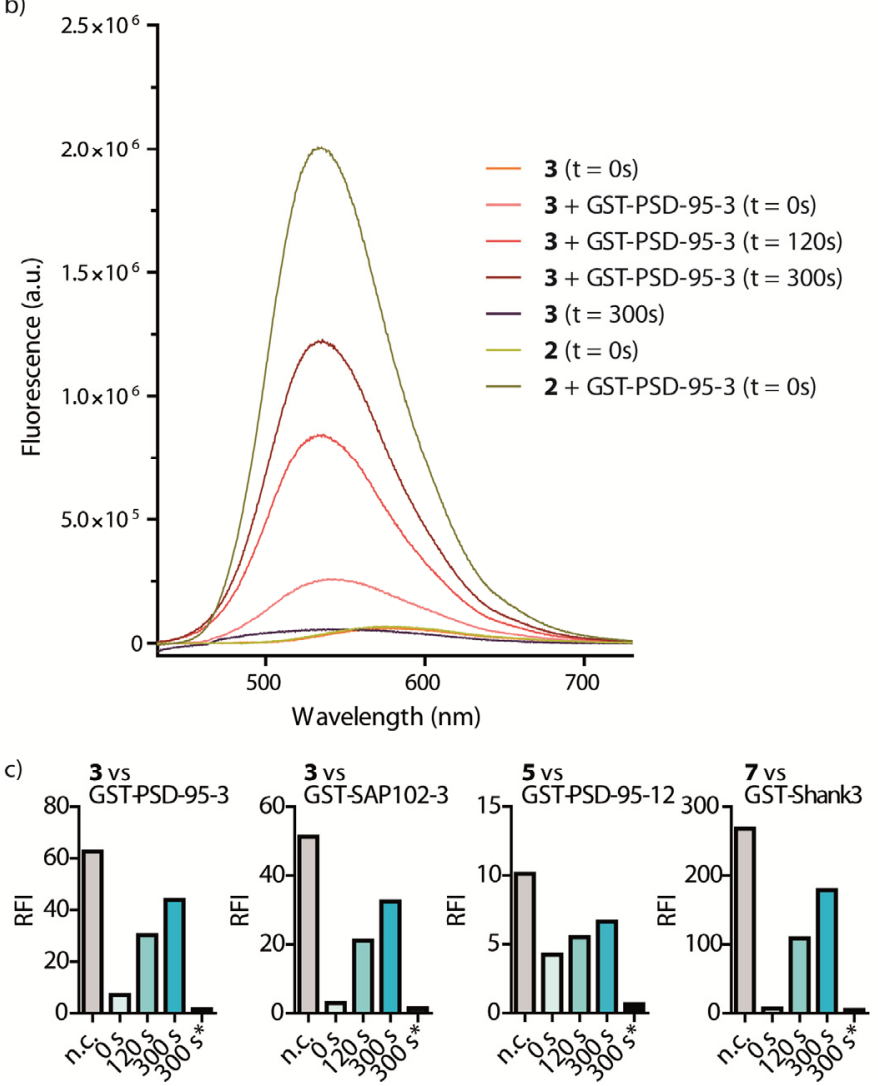

Fluorescence studies. a) Comparison of the fluorescence signal in presence (3 and 5 ) and absence of the NPE caging group ( 2 and 4$)$. All the peptides are at the same concentration $(2 \mu \mathrm{M})$. Within a given series of ligand $(2 / 3$ and $4 / 5)$, we do not observe any significant change in the fluorescence emission signal. b) Illustrative example of the fluorescence assay for binding recovery after uncaging and effects of irradiation on the probes fluorescence emission. Solutions of the caged and non-caged peptide, 3 and 2 respectively at $2 \mu \mathrm{M}$, were submitted to various durations of UV irradiation exposure $(365 \mathrm{~nm})$ in presence and absence of cognate PDZ domain (GST-PSD-95-3 at $20 \mu \mathrm{M}$ ). c) Relative fluorescence increase (RFI) of the caged probes in the presence of cognate PDZ domain(s) at increasing durations of irradiation at $365 \mathrm{~nm}(\mathrm{o}, 120$ and $300 \mathrm{~s})$. In each case, the RFI is obtained by comparison to levels of fluorescence obtained with the same amount of the corresponding unbound non-caged probe. The first entry (n.c.) corresponds to the parent noncaged probe in presence of PDZ domains ( $\mathbf{2}$ in the case of 3, $\mathbf{4}$ in the case of $\mathbf{5}$ and $\mathbf{6}$ in the case of $\mathbf{7}$ ) and the last entry in each graph $\left(300 \mathrm{~s}^{*}\right)$ corresponds to the RFI obtained with the caged ligand in the absence of PDZ domain(s) after $300 \mathrm{~s}$ irradiation. Note that in the case of $\mathbf{5}$ vs GST-PSD-95-12, two slightly different PDZ domains are present with different contribution to the local environment of the probe, which might account for the higher initial RFI (o s) compared to that observed for other caged ligand-PDZ domain complexes. 


\section{Figure S6}
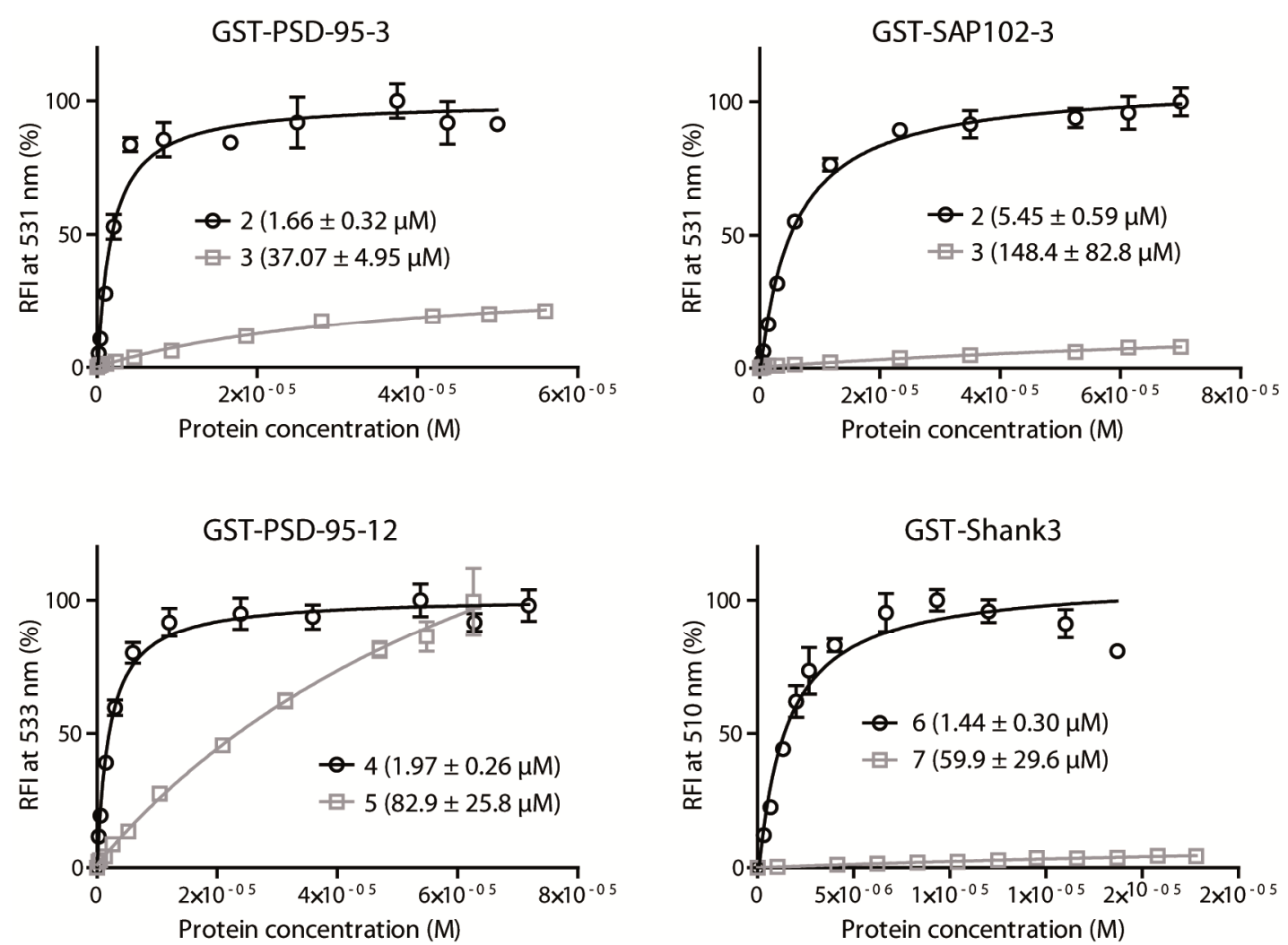

Comparative titrations of caged probes (grey) vs their respective non-caged analogues (black). For each PDZ domain construct, fluorescence levels were normalized to the levels obtained at saturation with the non-caged probes (2, 4 and 6). The data (squares plotted with standard error of the mean) were fitted (curves) using nonlinear leastsquares analysis to obtain the dissociation constants as described in the Supplementary Methods. The dissociation constants, $K_{D}$, are reported with the standard error. 


\section{Figure $\mathbf{S}_{7}$}

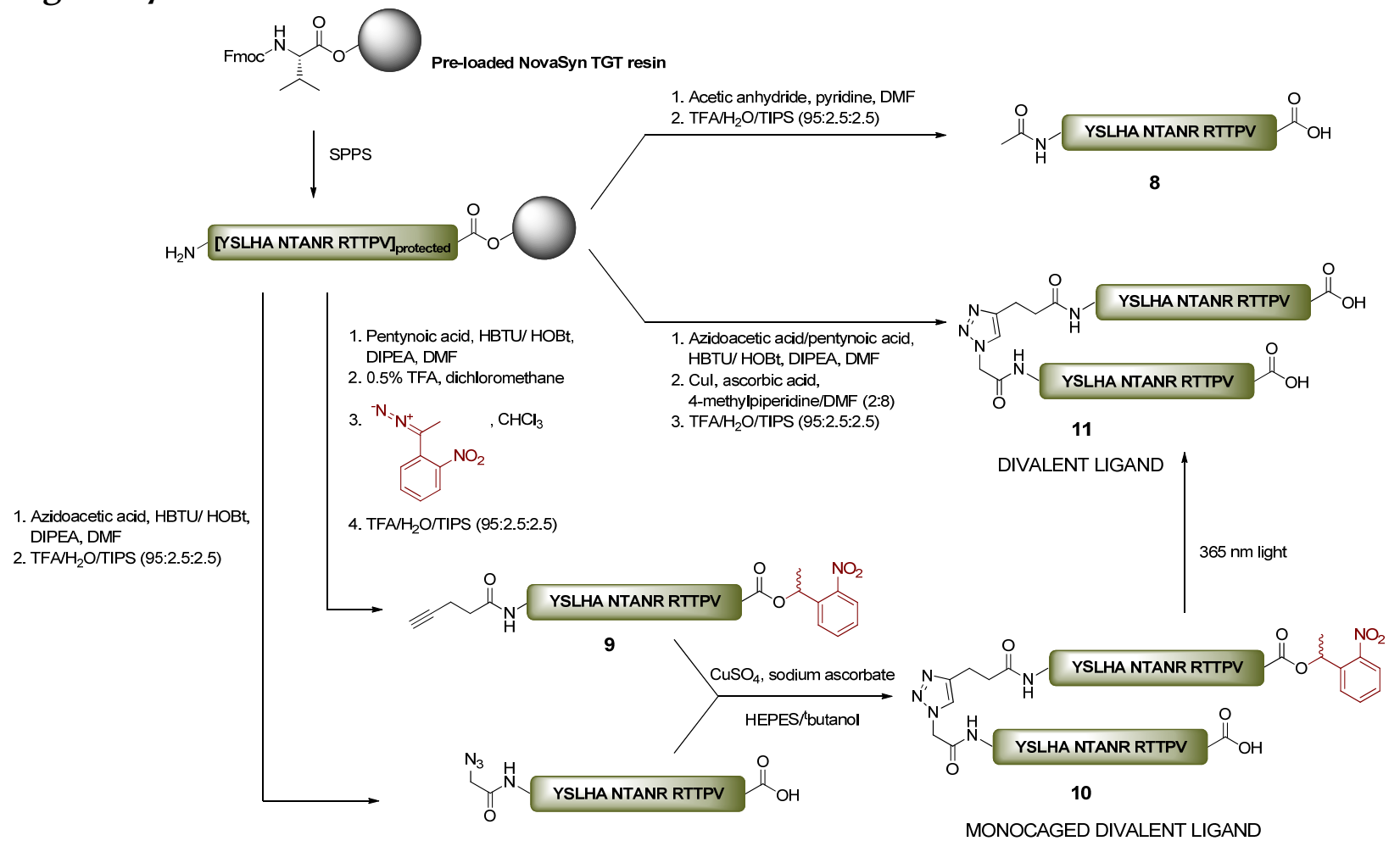

Syntheses and structures of the caged and non-caged divalent ligands (8-11). The symmetrical divalent ligand 11 was obtained as previously reported by on-resin ligation. ${ }^{[1]}$ 


\title{
Supporting Methods
}

\author{
Abbreviations \\ PDZ PSD-95/DLG/ZO-1 \\ MAGUK membrane-associated guanylate kinase \\ 4-DMAP 4-dimethylaminophthalimide \\ HBTU O-(benzotriazol-1-yl)- $N, N, N^{\prime}, N^{\prime}$-tetramethyluronium hexafluorophosphate \\ HOBt 1-hydroxy-benzotriazole \\ DCM dichloromethane \\ DMF N,N-dimethylformamide \\ DTT dithiothreitol \\ Dab L-2,4-diaminobutyric acid \\ DHB 2,5-dihydroxybenzoic acid \\ DIPEA N,N-diisopropylethylamine \\ EDTA ethylenediaminetetraacetic acid \\ GST glutathione S-transferase \\ NTA nitrilotriacetic acid \\ TFA trifluoroacetic acid \\ TEV tobacco etch virus \\ TIPS triisopropylsilane \\ Tris tris(hydroxymethyl)aminomethane
}

\section{PDZ domain cloning and expression}

\section{Cloning}

The third PDZ domain of SAP102 (SAP102-3, residues 393-493; primers: forward 5'-CGG GAT CCC TGG CTG AGG AAG ACT TTA CCA and reverse 5'-CCG CTC GAG TTA GGA TTC AAA GCG ACT GTA CTC) was PCR-amplified from the fulllength rat SAP102 gene (UniProtKB/Swiss-Prot entry Q62936) using the appropriate primers and inserted into the BamHI and XhoI sites of a home-made vector, pET-NO, which is derived from pET-32 (Novagen) and engineered to incorporate after the start codon an octahistidine tag immediately followed by a Tobacco Etch Virus cleavage site (ENLYFQS-) contiguous to the BamHI site. The PDZ domain GST-fusion constructs of PSD-95 (GST-PSD-95-1+2, residues 61-249 and GST-PSD-95-3, residues 302-402), SAP102 (GST-SAP102-3, residues 393-493) and Shank3 (GSTShank3, residues 633-747) have been previously described ${ }^{[2]}$.

\section{Expression and purification of recombinant PDZ domains}

Expression of the recombinant PDZ domains was performed in E. Coli BL21 codon plus ${ }^{\text {тм }}$ (DE3)-RIL cells by autoinduction following the methods described previously. Expression and purification of the GST fusion proteins proceeded as previously reported ${ }^{[2]}$. For the $\mathrm{His}_{8}$-tag-containing construct, (SAP102-3), the harvested cells were resuspended in ice-cold lysis buffer (10\% glycerol, $1 \%$ TritonX-10o, $1 \mathrm{mg} / \mathrm{mL}$ lysozyme in $50 \mathrm{mM}$ TrisOAc, $300 \mathrm{mM} \mathrm{NaCl}$ and $5 \mathrm{mM}$ imidazole, $\mathrm{pH}$ 8.o, containing protease inhibitor cocktail III from Calbiochem) at $\sim 1 / 10$ the original culture volume. Maintaining a working temperature of $4{ }^{\circ} \mathrm{C}$, the cells were lysed by sonication (Sonics VC505 at $40 \%$ amplitude for a total of 2 min with $1 \mathrm{~s}$ pulses and $1 \mathrm{~s}$ intervals) and the lysate were cleared by centrifugation at 15,334 $\mathrm{g}$ (40 min, 4 ${ }^{\circ} \mathrm{C}$ ). The octa-histidine construct was bound to Ni-NTA agarose resin (Qiagen) in batch using $\sim 5 \mathrm{~mL}$ of resin per liter of culture, overnight with gentle tumbling. The protein-bound resin was collected in fritted PolyPrep columns (BioRad) and washed with 10 volumes of $50 \mathrm{mM}$ TrisOAc, $300 \mathrm{mM} \mathrm{NaCl}(\mathrm{pH}$ 8.0) with an increasing amount of imidazole (from 5 to $25 \mathrm{mM}$ ) and the proteins were eluted with 2 volumes of a $50 \mathrm{mM}$ TrisOAc, $300 \mathrm{mM} \mathrm{NaCl}$ and $250 \mathrm{mM}$ imidazole solution ( $\mathrm{pH}$ 8.0). The eluted proteins were dialyzed against TEV cleavage buffer at $4 \stackrel{\circ}{\circ} \mathrm{C}(50 \mathrm{mM} \mathrm{Tris-HCl}, \mathrm{pH} 8.0,0.5$ mM EDTA, $150 \mathrm{mM} \mathrm{NaCl}, 1 \mathrm{mM}$ DTT). After equilibration, TEV protease (expressed and purified in our lab) was added directly to the dialysis bags. Upon completion of the tag removal, the protein was submitted to an additional dialysis step (20 mM Tris- $\mathrm{HCl}, 50 \mathrm{mM} \mathrm{NaCl}, \mathrm{pH}$ 8.o). The protein solution was filtered $(0.2 \mu \mathrm{m})$ and loaded at room temperature onto a Superdex ${ }^{\mathrm{TM}} 75$ HiLoad $^{\mathrm{TM}}{ }_{16 / 60}$ column (GE Healthcare) in a running buffer of 20 mM Tris. $\mathrm{HCl}$, 50 $\mathrm{mM} \mathrm{NaCl}, \mathrm{pH}$ 8.o, for further purification by size exclusion chromatography. Fractions containing monodispersed material were pooled and concentrated with Amicon ${ }^{\circledR}$ Ultra centrifugal filters (Millipore, 3,500 MW cut-off). For the crystallization trials, the final concentration of protein was $\sim 28 \mathrm{mg} / \mathrm{mL}$. 
Protein purity and identity were assessed by SDS-PAGE and western blot analysis when relevant (Anti-FLAG or Anti$\mathrm{His}_{6}$ antibodies). Protein concentrations were measured by UV absorbance at $280 \mathrm{~nm}$ in $6 \mathrm{M}$ guanidinium chloride using the molar extinction coefficients of tryptophan, tyrosine and cystine ${ }^{[3]}$ :

$\varepsilon_{280 \mathrm{~nm}}=(\#$ of Tryptophan $) \times 5,550+(\#$ of Tyrosine $) \times 1,490+(\#$ of Cystine $) \times 125$

Purified PDZ domains were used immediately or aliquoted, flash-frozen and stored at $-80{ }^{\circ} \mathrm{C}$ in their final purification buffer until use.

\section{Peptide and chemical synthesis}

\section{General}

All reagents for peptide synthesis were of analytical grade. Amino acid derivativess and reagents were obtained from GenScript, Anaspec, NovabioChem and Sigma-Aldrich. Fmoc-Val/Leu-NovaSyn ${ }^{\circledR}$ TGT resins (o.20 mmol/g) were obtained from NovaBiochem and Fmoc-PAL-PEG-PS resin ( $0.20 \mathrm{mmol} / \mathrm{g})$ was obtained from Applied Biosystems. 4DMAP anhydride (4-dimethylaminophthalenedicarboxilic anhydride) was synthesized according to the previously reported methods. ${ }^{[4]}$ Anhydrous DCM was distilled from calcium hydride.

\section{Peptide synthesis (SPPS) and fluorophore insertion}

Peptides were obtained by either manual synthesis or with an automated synthesizer (Advanced ChemTech automated synthesizer model $396 \Omega$ or Applied Biosystems 431A peptide synthesizer) by using standard Fmoc-based solid phase peptide synthesis procedures. Typically manual synthesis was performed on a 0.04 to 0.02 mmol scale with preloaded TGT resin ( 0.2 $\mathrm{mmol} / \mathrm{g})$ or PAL-PEG-PS resin ( $\sim 0.2 \mathrm{mmol} / \mathrm{g})$, using standard Fmoc-protected amino acid (6 equivalents), HBTU/HOBt as coupling reagents (6 equivalents each) and DIPEA (12 equivalents) in DMF or NMP. Coupling steps were conducted with a $50 \mathrm{mM}$ amino acid solution ( $1 \mathrm{~mL}$ per $100 \mathrm{mg}$ of resin) for 1 hour. Fmoc group deprotection was performed after each coupling step with a $20 \%$ solution of 4 -methyl-piperidine in DMF (vol/vol) for 3 $\times 5$ minutes. After removal of the N-terminal Fmoc group, the resulting free amine was capped with an acetyl group by using an acetic anhydride/pyridine solution (o.15 M each in DMF).

\section{4-DMAP incorporation}

Peptides incorporating the 4-DMAP environment-sensitive fluorophore were synthesized using the on-resin derivatization approach previously reported. ${ }^{[5]}$ Briefly, an Alloc-protected diaminoacid (Fmoc-L-Dab(Alloc)-OH from AnaSpec) was initially incorporated during the SPPS steps. After capping of the N-terminal amino group of the peptide sequence, the Alloc-protecting group was removed by resuspending the resin in dry dichloromethane (20 $\mathrm{mM}$ in peptide) with a stream of $\mathrm{N}_{2}$ bubbling through the solution for 5 minutes. $\mathrm{Pd}\left(\mathrm{PPh}_{3}\right)_{4}(\mathrm{o} .8$ equiv.) and phenylsilane (25 equiv.) were then added to the solution which was maintained under $\mathrm{N}_{2}$ bubbling for another 15 minutes. The resin was then washed with dichloromethane and DMF. The degassing/deprotection cycle was repeated two additional times. The resin containing the free side-chain amine was reacted with a solution of the anhydride form of 4-DMAP (4- $N, N$ dimethylaminophthalic anhydride, 2 equiv., $50 \mathrm{mM}$ ) and DIPEA (4 equiv.) in NMP. The mixture was allowed to stir overnight. The resin was then washed with DMF and dichloromethane and ring closure was performed by using a solution of HBTU/HOBt (6 equiv., $50 \mathrm{mM}$ ) in NMP or DMF with DIPEA (12 equiv.) for 2 hours. The resin was then washed with DMF and dichloromethane. The washing/coupling cycle was repeated two additional times in order to achieve full ring closure.

\section{Peptide-based ligand purification}

Peptides were deprotected and cleaved from the resin with a standard TFA/ $\mathrm{H}_{2} \mathrm{O} / \mathrm{TIPS}$ (95:2.5:2.5) cleavage cocktail for 2 $\mathrm{h} 30 \mathrm{~min}$ to $3 \mathrm{~h}$. TFA was evaporated with a stream of nitrogen until the peptides precipitated. The peptides were then triturated and precipitated three times in cold ether before purification by reverse phase HPLC on a semi-preparative column (YMC-Pack Pro $\mathrm{C}_{18}$, ODS-A 5/120, 250×20 mm) in water (o.1\% TFA) using an acetonitrile (o.1\% TFA) gradient and monitoring at $228 \mathrm{~nm}$ and $350 \mathrm{~nm}$. Peptides were stored in lyophilized form at $-80{ }^{\circ} \mathrm{C}$ until use.

\section{2-Nitracetophenone hydrazone synthesis}

The hydrazone (and diazo) derivative of 2-nitroacetophenone were prepared with the protocol reported by Walker et $a l .{ }^{[6]}$ with slight modifications. To a solution of 2-nitroacetophenone (1 mL, 1.240 g, $7.5 \mathrm{mmol}, 1$ equiv.) and hydrazine monohydrate $\left(800 \mu \mathrm{L}, 16.5 \mathrm{mmol}, 2.2\right.$ equiv.) in ethanol $(15 \mathrm{~mL})$ at $80{ }^{\circ} \mathrm{C}$ was added glacial acetic acid $(429 \mu \mathrm{L}, 7.5$ mmol, 1 equiv.). The reaction mixture was stirred at reflux for an hour. The ethanol was evaporated under vacuum and the residue was resuspended in chloroform and washed with water $(1 \times)$ and brine $(2 \times)$. The organic layer was dried over sodium sulfate and concentrated under vacuum to yield a yellow oil (yield $>95 \%$ ). The resulting oil was then dissolved in chloroform to give a stock solution of hydrazone for the next step. The stock solution was stored in an amber vial at 4 ${ }^{\circ} \mathrm{C}$. 


\section{Caged peptide synthesis}

The protected peptide was cleaved from the TGT resin by treatment with a $0.5 \%$ TFA solution in dichloromethane for 2 hrs. The beads were filtered off and the solution concentrated in vacuo. The solid residue was dissolved in dichloromethane and hexanes and concentrated two times. The resulting solid was transferred into amber Eppendorf tubes with dichloromethane in order to obtain $\sim$ 4-5 $\mu$ mol of protected peptide in each tube. The solvent was evaporated on a Speedivac system. For each tube, 10-15 molar equivalents of the hydrazone (stock solutions $\sim 100$ and $25 \mathrm{mg} / \mathrm{mL}$ ) were added to an amber Eppendorf tube containing manganese ${ }^{\text {IV }}$ oxide (1o equivalents compared to the hydrazone). The suspension was agitated for 30 min in the dark and $\mathrm{MnO}_{2}$ was fully spun down using a centrifuge. The resulting red solution was filtered on a pad of Celite (prepared beforehand in a Pasteur pipette with glass wool) directly into the tube containing the peptide. The reaction mixture was agitated for $20 \mathrm{hrs}$ in the dark. The reaction mixture was concentrated using a Speedivac concentrator. The peptide was deprotected with the standard cleavage cocktail (see above) for 2.5 hours and purified by RP-HPLC.

\section{Mono-caged divalent ligand synthesis}

The components for the monocaged divalent ligand synthesis were prepared by capping the Stargazin sequence (last 15 residues) prepared by Fmoc-based standard solid phase synthesis on Fmoc-Val-NovaSyn ${ }^{\circledR}$ TGT resins by either pentynoic acid or azidoacetic acid (freshly synthesized by reacting 1 equiv. of bromoacetic acid with 1 equiv. of sodium azide in DMF overnight and in the dark at a concentration of about $400 \mathrm{mM}$ ). The azido-derived peptide was directly cleaved, deprotected with the standard cleavage cocktail (see above) and purified by RP-HPLC whereas the alkynederived peptide was used to introduce the NPE caging group on the C-terminal carboxylate as described above prior to deprotection and purification. The $\mathrm{Cu}^{\mathrm{I}}$-catalyzed ligation was performed in a HEPES (10 mM, $\mathrm{pH}$ 7.o)/tert-butanol (1:1) solution containing $2.5 \mu \mathrm{mol}$ of both the azido- and alkyne-derived peptides (final concentration about $4 \mathrm{mM}$ for each peptide). Freshly prepared solutions of sodium ascorbate (4 equiv. from a $500 \mathrm{mM}$ stock solution in water) and $\mathrm{CuSO}_{4}$ ( 1 equiv. from a $100 \mathrm{mM}$ stock solution in water) were sequentially added in that order and the resulting mixture was vigorously agitated for 12 hrs in the dark under argon in a properly sealed container. The solution was then resuspended in 10 volume of water and directly purified by RP-HPLC.

\section{Peptide characterization (HPLC, MALDI, ESI) and quantification}

Peptide identity was confirmed by MALDI-TOF mass spectroscopy (MALDI-TOF, PerSeptive Biosystems Voyager) using DHB as a matrix or ESI mass spectroscopy (Mariner electrospray mass spectrometer, PerSeptive Biosystems). Purity was assessed by analytical reverse phase HPLC (YMC $\mathrm{C}_{18}$, ODS-A 5/120, 250×4.6 mm) using a standard gradient (5\% acetonitrile containing $0.1 \%$ TFA for $5 \mathrm{~min}$ followed by $5-95 \%$ acetonitrile containing $0.1 \%$ TFA over 50 min in water containing $0.1 \%$ TFA at a flow rate of $\left.1 \mathrm{~mL} \cdot \mathrm{min}^{-1}\right)$. All the peptides were more than $95 \%$ pure as judged by analytical HPLC. The final peptides were quantified using molar extinction coefficients of 4 -DMAP $\left(\varepsilon_{421 \mathrm{~nm}}=6480 \mathrm{M}^{-1}\right.$. $\mathrm{cm}^{-1}$ in water $)$ or $\operatorname{NPE}\left(\varepsilon_{350 \mathrm{~nm}}=500 \mathrm{M}^{-1} \cdot \mathrm{cm}^{-1}\right.$ in water $) .{ }^{\left[7^{7}\right.}$

\section{Buffers}

\section{Phosphate buffer saline solution (PBS 10x)}

10x PBS consists of $1.5 \mathrm{M} \mathrm{NaCl}, 50 \mathrm{mM} \mathrm{Na}_{2} \mathrm{HPO}_{4}$ and $50 \mathrm{mM} \mathrm{NaH}_{2} \mathrm{PO}_{4}$ in distilled water, adjusted to pH 7.4. A 1x solution is obtained by a ten-fold dilution of the $10 \mathrm{x}$ in distilled water. Solvents were filtered before spectroscopic applications (with $0.45 \mu \mathrm{m}$ PVDF membranes).

\section{Structural biology}

\section{Crystallization}

Crystals of SAP102-3 bound to the fluorogenic ligand 1 were grown at $4{ }^{\circ} \mathrm{C}$ using the hanging drop vapor diffusion method. The crystallization drops were formed by mixing $1.2 \mu \mathrm{L}$ of protein solution at a concentration of $28 \mathrm{mg} / \mathrm{mL}$ containing 1.1 equivalent of 1 with $1.2 \mu \mathrm{L}$ of reservoir solution containing $1 \mathrm{M}$ sodium citrate, o.1 $\mathrm{M} \mathrm{Tris.HCl} \mathrm{pH} \mathrm{8.5.}$ Crystals were cryoprotected in a reservoir solution supplemented with $12.5 \%$ glycerol.

\section{Data collection, structure determination and refinement}

Data sets from a single ligand-bound SAP102-3 PDZ domain crystal were collected on the NSLS beamline X6A at Brookhaven National Laboratory (Upton, NY) tuned to a wavelength of $0.9795 \AA$ and at 100 K with a frame oscillation of $1^{\circ}$ using the ADSC Quantum 270 detector. Indexing and integration of the collected images were accomplished using the HKL2ooo suite of programs ${ }^{[8]}$. Intensities were converted to structure factors using the program Truncate. The ligand domain structure was solved by molecular replacement with the program PHASER ${ }^{[9]}$ using coordinates of the 
third PDZ domain from DLG4/PSD-95 (PDB accession codes: 3JVQ). The unambiguous solution contained two complexes in the asymmetric unit. The fluorogenic ligand was clearly visible from the initial $F_{o}-F_{c}$ difference electron density map. Subsequent model building and refinement were carried out using COOT ${ }^{[10]}$ and Refmac $5^{[11]}$, respectively. Solvent building was accomplished using ARP/wARP ${ }^{[12]}$ and model statistics monitored using PROCHECK ${ }^{[13]}$ and MolProbity ${ }^{[14]}$. Ramachandran analysis indicated that $92.4 \%$ of the residues reside in the most favorable regions, with the remaining $7.0 \%$ and $0.6 \%$ in additionally allowed and generously allowed regions, respectively. All structural figures were prepared with PyMOL ${ }^{[15]}$. Refinement details can be found in Supplementary Table 2.

\section{Uncaging}

Caged ligands were irradiated in a closed quartz vessel with a $1 \mathrm{~mm}$ path length on a UVP High Performance Ultraviolet Transilluminator with light centered at $365 \mathrm{~nm}\left(7330 \mu \mathrm{W} / \mathrm{cm}^{2}\right)$.

\section{Uncaging monitoring (HPLC assay)}

The effect of $365 \mathrm{~nm}-\mathrm{UV}$ irradiation was assessed on solutions of a caged or a non-caged probe derived from the Stargazin C-terminal sequence -3 and 2 respectively- in PBS (20 $\mu \mathrm{M}$ in ligand) supplemented with $5 \mathrm{mM}$ DTT. The starting solutions (o s) and the irradiated solutions (6o, 120 and $300 \mathrm{~s}$ ) were analyzed and quantified at $421 \mathrm{~nm}$ by analytical reverse phase HPLC (YMC $C_{18}$, ODS-A 5/120, 250×4.6 mm) using a standard gradient $(5 \%$ acetonitrile containing $0.1 \%$ TFA for 5 min followed by $5-95 \%$ acetonitrile containing $0.1 \%$ TFA over 50 min in water containing $0.1 \%$ TFA at a flow rate of $1 \mathrm{~mL} \cdot \mathrm{min}^{-1}$ ). The main peak identities were confirmed by mass spectroscopy.

\section{Uncaging monitoring (Fluorescence-based assay)}

Recovery of the PDZ domain probe fluorescence emission after uncaging was monitored on PBS solutions supplemented with $5 \mathrm{mM}$ DTT containing $20 \mu \mathrm{M}$ of recombinant PDZ domains and $2 \mu \mathrm{M}$ of their respective probes (caged or non-caged: 3 or $\mathbf{2}$ for GST-PSD-95-3 and GST-SAP102-3, 5 or $\mathbf{4}$ for GST-PSD-95-12, and $\mathbf{7}$ or $\mathbf{6}$ for GST-Shank3). The fluorescence signal from each solution was recorded prior to any UV exposure and after 120 and $300 \mathrm{~s}$ irradiation at $365 \mathrm{~nm}$. The relative fluorescence increase was quantified as described below (Fluorescence Studies).

\section{Light-assisted disruption of PDZ domain mediated interactions (Fluorescence-based assay)}

Photoactivation of the caged competing ligand was assessed in PBS solutions supplemented with 5 mM DTT and containing $5 \mu \mathrm{M}$ of probe $2,5 \mu \mathrm{M}$ of GST-PSD-95-3, and $100 \mu \mathrm{M}$ of a non-fluorescent competing ligand (either noncaged, 8, or caged, 9). Solutions were irradiated at $365 \mathrm{~nm}$ for $300 \mathrm{~s}$. Fluorescence emission was recorded as described below (Fluorescence Studies) in $100 \mu \mathrm{L}$ nominal volume cuvettes. Each condition was repeated at least three times and the final results averaged.

\section{Fluorescence studies}

\section{Materials and general methods}

Fluorescence spectra were recorded on a Fluoromax 3 instrument (Horiba Jobin Yvon) in $1 \mathrm{~cm}$ path length quartz cells (100 $\mu \mathrm{L}$ nominal volume from Starna Cells). All measurements were performed at a constant temperature of $25{ }^{\circ} \mathrm{C}$. The spectra were corrected for emission intensity by using manufacturer-supplied correction factors. Slit widths were $3 \mathrm{~nm}$ for excitation and $6 \mathrm{~nm}$ for emission. The 4-DMAP fluorophore was excited at $421 \mathrm{~nm}$ and the spectra were recorded between $432 \mathrm{~nm}$ and $730 \mathrm{~nm}$ (0.5 $\mathrm{nm}$ increments and o.1 s integration time).

\section{Relative fluorescence increases}

The fluorescence increase measurements were performed at $25{ }^{\circ} \mathrm{C}$ in PBS buffer $(\mathrm{pH} 7.4$, complemented with 5 mM DTT) comparing solutions of (1) $2 \mu \mathrm{M}$ of 4-DMAP-containing peptide alone in PBS and (2) $2 \mu \mathrm{M}$ of 4-DMAP-containing peptide with $20 \mu \mathrm{M}$ of PDZ domain construct in PBS. Blanks consisting of PBS for (1) and PBS with $20 \mu \mathrm{M}$ of the corresponding PDZ domain construct for (2) were subtracted from the respective spectra. Each final spectrum resulted from the average of at least three independent runs. The relative fluorescence increases for each series of peptides and PDZ domain(s) were evaluated by comparing the resulting averaged fluorescence emission intensities of (2) and (1) at the wavelength of maximal emission of (2). Ratios were calculated over a $5 \mathrm{~nm}$ range centered on the wavelength of maximal emission of (2) and the values were averaged to yield the reported final ratio.

\section{Fluorescence titration}

For each titration, the peptide concentration was kept constant (around 2 to $4 \mu \mathrm{M}$ ) and the protein concentration was varied from values lower or close to the anticipated $K_{D}$ to saturation of the fluorescence signal increase. A $130 \mu \mathrm{L}$ 
solution in PBS ( $\mathrm{pH}_{7.4}$ ) was prepared for each protein concentration. Dissociation constants were evaluated using the following equation ${ }^{[16]}$ by nonlinear least-squares analysis using the program GraphPad Prism:

$$
F=F_{0}+\frac{\left(F_{\max }-F_{0}\right) \times \frac{[\text { Prot }]}{K_{d}}}{1+\frac{[\text { Prot }]}{K_{d}}}
$$

where $\mathrm{F}$ is the fluorescence reading, [Prot] is the protein concentration in mol. $\mathrm{L}^{-1}$, Kd is the dissociation constant of the PDZ domain and peptide, $F_{o}$ is the initial fluorescence value (fraction bound $=0$ ), and $F_{\max }$ is the fluorescence value at saturation (fraction bound $=1$ ). Each $\mathrm{Kd}$ value is the average of at least three independent experiments. Data obtained with PSD-95 tandem PDZ domains (GST-PSD-95-1+2) were fitted as with single domains to yield apparent dissociation constants. For each PDZ domain(s) construct, RFI were normalized to the value obtained at saturation with the noncaged ligand.

\section{Competitive titrations.}

Competition experiments were conducted on $450 \mu \mathrm{L}$ of a PBS ( $\mathrm{pH} 7.4$ ) solution containing $5 \mu \mathrm{M}$ of fluorescent probe (2) and $5 \mu \mathrm{M}$ of PDZ domains (GST-PSD-95-12). The non-fluorescent ligand solution was added sequentially in small volumes to achieve a range of concentrations from $1 \mathrm{nM}$ to $2 \mathrm{mM}$. The titrations were done at least in triplicate and averaged. The $K_{i}$ were obtained by fitting the relative fluorescence increase (RFI, obtained as described above) of the averaged spectrum to the logarithm of the non-fluorescent peptide concentration (Log[nFP], Molar) using the Competitive Binding: One Site model from GraphPad Prism 5 software with the following equations:

$$
\begin{aligned}
& \log (E C 50)=\log \left(10^{\log K_{i}} *\left(1+\frac{[F P]}{K_{D}^{F l u o}}\right)\right) \\
& R F I=\min _{R F I}+\frac{\left(\max _{R F I}-\min _{R F I}\right)}{\left(1+10^{(\log [n F P]-\log E C 50)}\right)}
\end{aligned}
$$

where $[\mathrm{FP}]$ is the concentration of the fluorescent peptide (constant), $\mathrm{K}_{\mathbf{D}}$ Fluo is the dissociation constant of the fluorescent peptide with the corresponding PDZ domain (constant, same unit as [FP]; here for probe 2 with GST-PSD$95-12, K_{\mathrm{D}}^{\text {Fluo }}=5.99 \pm 0.76 \mu \mathrm{M}$ ), $\min _{\mathrm{RFI}}$ and $\max _{\mathrm{RFI}}$ correspond respectively to 1 (i.e., no fluorescence increase) and the RFI in the absence of competing ligand.

\section{References}

[1] M. Sainlos, C. Tigaret, C. Poujol, N. B. Olivier, L. Bard, C. Breillat, K. Thiolon, D. Choquet, B. Imperiali, Nat. Chem. Biol. 2011, 7, 81-91.

[2] M. Sainlos, W. S. Iskenderian, B. Imperiali, J. Am. Chem. Soc. 20o9, 131, 6680-6682.

[3] S. C. Gill, P. H. Vonhippel, Anal. Biochem. 1989, 182, 319-326; C. N. Pace, F. Vajdos, L. Fee, G. Grimsley, T. Gray, Protein Sci. 1995, 4, 2411-2423.

[4] M. Sainlos, B. Imperiali, Nat. Protoc. 2007, 2, 3219-3225.

[5] M. Sainlos, B. Imperiali, Nat. Protoc. 2007, 2, 3201-3209.

[6] J. W. Walker, G. P. Reid, J. A. McCray, D. R. Trentham, J. Am. Chem. Soc. 1988, 110, 7170-7177.

[7] D. V. Sarkisov, S. S. Wang, Nat. Protoc. 2oo6, 1, 828-832.

[8] Z. Otwinowski, W. Minor, Meth. Enzymol. 1997, 276, 307-326.

[9] A. J. McCoy, J. Appl. Crystallogr. 2007, 40, 658-674.

[10] P. Emsley, K. Cowtan, Acta Crystallogr. D Biol. Crystallogr. 2004, 6o, 2126-2132.

[11] G. N. Murshudov, A. A. Vagin, E. J. Dodson, Acta Crystallogr. D Biol. Crystallogr. 1997, 53, $240-255$.

[12] V. S. Lamzin, K. S. Wilson, Acta Crystallogr. D Biol. Crystallogr. 1993, 49, 129-147.

[13] R. A. Laskowski, M. W. MacArthur, D. S. Moss, J. M. Thornton, J. Appl. Crystallogr. 1993, 26, $283-291$.

[14] I. W. Davis, Nucleic Acids Res. 2007, 35, W375-W383.

[15] W. L. DeLano, The PyMOL Molecular Graphics System, Delano Scientific, Palo Alto, CA, USA, 2002.

[16] B. Z. Harris, B. J. Hillier, W. A. Lim, Biochemistry 2oo1, 40, 5921-5930. 